\title{
Foliar photochemical processes and carbon metabolism under favourable and adverse winter conditions in a Mediterranean mixed forest, Catalonia (Spain)
}

\author{
D. Sperlich ${ }^{1,2}$, C. T. Chang ${ }^{1,2}$, J. Peñuelas ${ }^{1,3}$, C. Gracia ${ }^{1,2}$, and S. Sabaté ${ }^{1,2}$ \\ ${ }^{1}$ Centre for Ecological Research and Forestry Applications (CREAF), Universitat Autonoma de Barcelona, \\ 08193 Bellaterra, Barcelona, Spain \\ ${ }^{2}$ Departament d'Ecologia, Facultat de Biologia, Universitat de Barcelona, Diagonal 645, 08028 Barcelona, Spain \\ ${ }^{3}$ Global Ecology Unit CSIC-CEAB-CREAF, CREAF, Facultat de Ciencies, Universitat Autònoma de Barcelona, \\ 08913 Bellaterra, Spain
}

Correspondence to: D. Sperlich (dominik@creaf.uab.es)

Received: 25 April 2014 - Published in Biogeosciences Discuss.: 20 June 2014

Revised: 27 August 2014 - Accepted: 10 September 2014 - Published: 16 October 2014

\begin{abstract}
Evergreen trees in the Mediterranean region must cope with a wide range of environmental stresses from summer drought to winter cold. The mildness of Mediterranean winters can periodically lead to favourable environmental conditions above the threshold for a positive carbon balance, benefitting evergreen woody species more than deciduous ones. The comparatively lower solar energy input in winter decreases the foliar light saturation point. This leads to a higher susceptibility to photoinhibitory stress especially when chilly $\left(<12{ }^{\circ} \mathrm{C}\right)$ or freezing temperatures $\left(<0^{\circ} \mathrm{C}\right)$ coincide with clear skies and relatively high solar irradiances. Nonetheless, the advantage of evergreen species that are able to photosynthesize all year round where a significant fraction can be attributed to winter months, compensates for the lower carbon uptake during spring and summer in comparison to deciduous species. We investigated the ecophysiological behaviour of three co-occurring mature evergreen tree species (Quercus ilex L., Pinus halepensis Mill., and Arbutus unedo L.). Therefore, we collected twigs from the field during a period of mild winter conditions and after a sudden cold period. After both periods, the state of the photosynthetic machinery was tested in the laboratory by estimating the foliar photosynthetic potential with $\mathrm{CO}_{2}$ response curves in parallel with chlorophyll fluorescence measurements. The studied evergreen tree species benefited strongly from mild winter conditions by exhibiting extraordinarily high photosynthetic potentials. A sudden period of frost, however, neg-
\end{abstract}

atively affected the photosynthetic apparatus, leading to significant decreases in key physiological parameters such as the maximum carboxylation velocity $\left(V_{\mathrm{c}, \max }\right)$, the maximum photosynthetic electron transport rate $\left(J_{\max }\right)$, and the optimal fluorometric quantum yield of photosystem II $\left(F_{\mathrm{v}} / F_{\mathrm{m}}\right)$. The responses of $V_{\mathrm{c}, \max }$ and $J_{\max }$ were highly species specific, with $Q$. ilex exhibiting the highest and $P$. halepensis the lowest reductions. In contrast, the optimal fluorometric quantum yield of photosystem II $\left(F_{\mathrm{v}} / F_{\mathrm{m}}\right)$ was significantly lower in A. unedo after the cold period. The leaf position played an important role in $Q$. ilex showing a stronger winter effect on sunlit leaves in comparison to shaded leaves. Our results generally agreed with the previous classifications of photoinhibition-tolerant (P. halepensis) and photoinhibitionavoiding $(Q$. ilex) species on the basis of their susceptibility to dynamic photoinhibition, whereas $A$. unedo was the least tolerant to photoinhibition, which was chronic in this species. Q. ilex and P. halepensis seem to follow contrasting photoprotective strategies. However, they seemed equally successful under the prevailing conditions exhibiting an adaptive advantage over $A$. unedo. These results show that our understanding of the dynamics of interspecific competition in Mediterranean ecosystems requires consideration of the physiological behaviour during winter which may have important implications for long-term carbon budgets and growth trends. 


\section{Introduction}

Mediterranean-type ecosystems are widely associated with broadleaved evergreen sclerophyllous shrubs and trees, the classic vegetation types in climates where hot and dry summers alternate with cool and wet winters (Aschmann, 1973; Blumler, 1991; Orshan, 1983; Specht, 1969). In summer, water is undoubtedly the most important factor limiting growth and survival in the Mediterranean region, whereas spring and autumn provide better growing conditions (Gracia et al., 1999; Orshan, 1983; Sabaté and Gracia, 2011). In winter, the low temperatures and solar radiation limit the amount of energy available for the vegetation, although soil water contents and water pressure deficits are favourable. This highly dynamic seasonality of favourable and unfavourable conditions produces a rich diversity of plants in these regions (Cowling et al., 1996). In turn, this features a highly diverse range of traits and taxa that has produced multiple survival strategies which help to explain the abundance and distribution of species (Matesanz and Valladares, 2014). Nonetheless, the predicted reductions in annual precipitation, increases in mean temperature, and increases in the variability and occurrence of extreme droughts and heat waves in arid and semiarid regions are likely to affect species abundance and distribution (Friend, 2010; IPCC, 2013; Somot et al., 2008). The battle for survival and dominance in plant communities facing these novel changes in their environments evokes great uncertainties and worries in the scientific community concerning the adaptive ability, distribution shifts, or, at worst, local extinction of species especially in Mediterranean type ecosystems (Matesanz and Valladares, 2014; Peñuelas et al., 2013).

In this context, a pivotal role devolves on the winter period in Mediterranean type climates as mild winter temperatures can suddenly provide potential periods of growth and recovery from stressful summer drought periods, above all for evergreen trees. Thus, the success in the future dynamics of competition and novel environmental conditions will not only depend upon the tolerance to withstand abiotic stresses, but also on their effectiveness to benefit rapidly from periods when environmental conditions may be favourable such as in winter. The effective acclimation of the photosynthetic apparatus during winter was hereby in the focus of interest for this study. This acclimation is particularly essential for evergreen tree species in order to compensate for their lower photosynthetic rates during the growth period, relative to deciduous species. Plants have evolved diverse adaptive mechanisms to cope with the consequences of stress and to acclimate to low temperatures (Blumler, 1991; Öquist and Huner, 2003).

Hereby, mixed forests provide us with an ideal test-bed for investigating the different ecophysiological strategies and their sensitivities to abiotic stresses, because all tree species have to contend equally with the yearly variability of environmental conditions. Nevertheless, most ecophysiological studies have been conducted in spring and summer, and winter has been surprisingly overlooked despite its importance for our understanding of the dominance of certain vegetation types and of the responses of vegetation to stress, seasonality and species composition (Oliveira and Peñuelas, 2004; Orshan, 1983; Tretiach et al., 1997). Even though efforts have recently been made to elucidate the behaviour of sclerophyllous ecosystems under variable winter conditions (e.g. García-Plazaola et al., 1999, 1997; Kyparissis et al., 2000; Levizou et al., 2004; Martínez-Ferri et al., 2004; Oliveira and Peñuelas, 2004, 2000), the physiological behaviour of co-occurring species of evergreen trees in the Mediterranean region, including leaf gas exchange (GE) and chlorophyll fluorescence (CF) methods, have been insufficiently studied for understanding the dynamics of photoinhibitory stress and interspecific competition. Therefore, in our study we used an ample set of parameters from GE \& CF measurements in order to provide a snapshot in the plant's physiology and in order to characterize in detail the effects on the photosynthetic light and carbon reactions during winter (Flexas et al., 2008; Guidi and Calatayud, 2014). This study was conducted on three species of evergreen trees (Quercus ilex L., Pinus halepensis Mill., Arbutus unedo L.) in northern Catalonia near Barcelona, Spain.

Our aims were to (i) investigate the foliar physiology of these three species under mild winter conditions, (ii) analyse the effect of sudden changes from favourable to unfavourable conditions on photochemical and non-photochemical processes associated with electron transport, $\mathrm{CO}_{2}$ fixation and heat dissipation, (iii) determine whether leaves exhibit distinct locational (sunlit or shaded) responses to winter stress, and (iv) identify the species-specific strategies when coping with stress, induced by low temperatures and frost. These topics are of particular interest due to the recent report of an increased dominance of angiosperm trees and the negative impacts on pines over extensive areas of the Iberian Peninsula (Carnicer et al., 2013). Therefore, we must improve our understanding of the interactions among co-occurring tree species competing for scarce resources and trying to survive and tolerate novel environmental conditions to be able to predict ecosystem responses to global climate change.

\section{Material and methods}

\subsection{Field site}

Our experiment was conducted at the field station of Can Balasc in Collserola Natural Park, a coastal massif (8500 ha) in the hinterlands of Barcelona, northeastern Spain $\left(41^{\circ} 25^{\prime} \mathrm{N}\right.$, $2^{\circ} 04^{\prime} \mathrm{E}, 270 \mathrm{~m}$ a.s.l.). The forest stand at the study site has an area of $0.7 \mathrm{ha}$ and is on a northeast-facing slope. The climate is characterized by typical Mediterranean seasonal summer droughts and warm temperatures, with a mean August temperature of $22.8^{\circ} \mathrm{C}$. The proximity to the Mediterranean Sea provides mild winters where frosts and snow are rare, as 
reflected in the mean January temperature of $7.9^{\circ} \mathrm{C}$. Mean annual precipitation and temperature are $723 \mathrm{~mm}$ and $15.1^{\circ} \mathrm{C}$ (1951-2010), respectively (Ninyerola et al., 2000). The soils have predominantly developed above lithological strata of shales and granite (Sanchez-Humanes and Espelta, 2011). Sensors for measuring air temperature (HMP45C, Vaisala Oyj, Finland) and solar radiation (SP1110 Skye Instruments Ltd, Powys, UK) were installed at a height of $3 \mathrm{~m}$, in a clearing ca. $1 \mathrm{~km}$ from the plot.

\subsection{Stand history and composition of tree species}

The history of Collserola Natural Park is typical for the area, being characterized by intensive exploitation for charcoal in Quercus coppice forests and for agricultural purposes such as olive production until the 20th century. The abandonment of these practices at the beginning of the 20th century led to forest succession and restoration with the early successional and fast growing Aleppo Pine (P. halepensis Mill.). As in wide parts of the Mediterranean basin, this tree species was favoured by forest management for its rapid growth rates and timber yields (Maestre and Cortina, 2004). The cessation of forest practices in the early 1950s led to a second wave of succession characterized by extensive regeneration of the evergreen Holm Oak ( $Q$. ilex L.) and the deciduous Pubescent Oak ( $Q$. pubescens Willd.). As a result, many mixed forest stands in Collserola are currently characterized by twolayered canopies consisting of a dense layer from Quercus species surmounted by shelter trees of $P$. halepensis. The forest stand at our experimental site has reached the next and final stage of forest succession, where the dense Quercus canopy is out-competing the early successional $P$. halepensis, simply by suppressing the growth of the light-demanding pine seedlings and saplings. This final stage of succession is typical of many pine-oak forest sites in the Iberia Peninsula. $P$. halepensis is dependent mainly on fire disturbances for natural regeneration (Zavala et al., 2000). Interestingly, the diversity of tree species is enriched by the scattered occurrence of Strawberry trees (A. unedo) in the forest canopy being usually more characterized as a shrubby species widely abundant in the macchia ecosystems of the Iberian peninsula (Beyschlag et al., 1986; Reichstein et al., 2002). Its existence adds an ecological value to the forest due to its flowering and fruiting behaviour attracting insects and birds. It raises questions about its performance as a mature tree within the interspecific competition of this mixed forest. The forest diversity also encompasses a dense understorey mainly consisting of Pistacia lentiscus L., Erica arborea L., Phillyrea latifolia L., Rhamnus alaternus L., Cistus spp, Crataegus monogyna Jacq., Bupleurum fruticosum L. and other less abundant species. The stand at our study site has reached a highly diverse stage of forest succession and has provided us with a rare set of some of the most important Mediterranean tree species growing together naturally.

\subsection{Sampling}

The sampling of the mild winter period took place in the period 9-19 January 2012 (DOY 9-19). The frosty/chilly period lasted from 19 January-4 February 2012 (DOY 21-35). The sampling period after the frosty/chilly period took place between 14 and 24 February 2012 (DOY 45-55). We obtained sunlit leaves for GE analyses by sampling five twigs with a pruning pull from the outer part of the upper third of the crown, and shaded leaves by sampling five twigs from the inner part of the crown, optimally at similar heights. In the second field campaign after the frost occurrence, however, we were constrained to sample shaded leaves only from $Q$. ilex due to limitation in labour and equipment. The shaded leaves of $P$. halepensis and A. unedo could only be sampled in the first, but not in the second field campaign. The twigs were immediately re-cut under water in buckets in the field and transported to the laboratory retained in plastic bags to minimize transpiration. Five replicates of each species were collected for the analysis of GE. The twigs were pre-conditioned in the laboratory at a room temperature of $24-28^{\circ} \mathrm{C}$ in $\operatorname{dim}$ light for $1-3 \mathrm{~d}$ and freshly cut the following morning before the measurement of GE (Niinemets et al., 1999, 2005). We intended to avoid the problems we had faced in the field, such as the limited ability of the instruments to reach the standard operating temperature of $25^{\circ} \mathrm{C}$, which was hampered by low ambient temperatures or unpredictable plant responses such as closed stomata or patchy stomatal conductance (Mott and Buckley, 1998, 2000). The pre-conditioned twigs instead had a stable $C_{\mathrm{i}}$ and sufficiently high $g_{\mathrm{s}}$, which are required for conducting a noise-free $\mathrm{CO}_{2}$-response curve. The method of cutting twigs rehydrated stressed leaves at optimum conditions and allowed us to analyse their longterm acclimation to the environmental conditions from which they were derived. This method has been used in other studies (Epron and Dreyer, 1992; Haldimann and Feller, 2004; Laisk et al., 2002; Niinemets et al., 1999, 2005), and we confirmed that the leaves remained fresh and functional for several days controlled by $g_{\mathrm{s}}$ and fluorescent signals (data not shown). Our ambient values of the GE- and CF-derived parameters accordingly represented the "ambient capacity" of pre-conditioned leaves under near-optimal ambient environmental conditions of $\mathrm{CO}_{2}$ concentrations and saturating light and at a room temperature of $20-25^{\circ} \mathrm{C}$ (Reich et al., 1998).

\subsection{GE and CF analyses}

GE and CF were measured with a Li-Cor LI-6400XT Portable Photosynthesis System equipped with a LI-640040 Leaf Chamber Fluorometer (Li-Cor, Inc., Lincoln, NE, USA). Response curves for foliar net assimilation versus $\mathrm{CO}_{2}$ concentration were recorded from five apparently healthy leaves per tree species and leaf position. CF was measured in parallel. A. unedo leaves were sufficiently large to cover the leaf cuvette $\left(2 \mathrm{~cm}^{2}\right)$, whereas sunlit leaves of 
Q. ilex were in some cases too small, and the area of the leaves had to be adjusted after the measurements. For the leaves of $P$. halepensis, we positioned a layer of needles (approx. 10-15) on the leaf cuvette, avoiding gaps and overlays. The putty-like adhesive "Blu-tack" (Bostik SA, La Plaine St Denis, France) was also used to seal the gaskets and to keep the needles in position.

\subsubsection{Preparation and acclimation}

Prior to recording the response curves, the temperature of the clamped leaves ( $\left.T_{\text {Leaf }}\right)$ was adjusted to $25^{\circ} \mathrm{C}$, and the flow of ambient $\mathrm{CO}_{2}$ in the leaf chamber $\left(C_{\mathrm{a}}\right)$ was set to $400 \mu \mathrm{mol} \mathrm{CO}_{2} \mathrm{~m}^{-2} \mathrm{~s}^{-1}$ (controlled with a $\mathrm{CO}_{2}$ mixer). The leaves were dark-adapted for 15-20 min before the measurements, and the data were logged when the GE-derived parameters such as stomatal conductance $\left(g_{\mathrm{s}}\right)$, stomatal internal $\mathrm{CO}_{2}$ concentration $\left(C_{\mathrm{i}}\right)$ and mitochondrial respiration in darkness $\left(R_{\mathrm{n}}\right)$ had stabilized. For our purposes, darkadaption did not necessarily mean strict prolonged darkness but referred to a sufficiently low level of ambient background light that did not cause an accumulation of reduced photosystem II (PSII) acceptors, which could be detected as an increase in fluorescence. The leaves were also pre-darkened with special leaf clips or a dark cloth to save time. The chamber light was then turned on at a saturating quantum flux density of $1000 \mu \mathrm{mol}$ photons $\mathrm{m}^{-2} \mathrm{~s}^{-1}$ (20\% blue LED, $80 \%$ red LED). The relatively high percentage of blue light stimulated the stomata to open (Farquhar and Sharkey, 1982; Kang et al., 2009; Niinemets et al., 2005). The relative humidity was maintained at $50 \%( \pm 10 \%)$, and the air flow was maintained at $500 \mu \mathrm{mol} \mathrm{s}{ }^{-1}$. The above conditions were maintained for approximately 20-30 min until the net rate of carbon assimilation $\left(A_{\mathrm{net}}\right), g_{\mathrm{s}}$, and $C_{\mathrm{i}}$ of the leaf stabilized.

The GE-derived parameters $A_{\text {net }}, g_{\mathrm{s}}$, and $C_{\mathrm{i}}$ likely require less time to stabilize, especially in healthy and unstressed leaves, but this minimum time range was necessary for the $\mathrm{CF}$-derived parameters to ensure accurate measurement of the efficiency of harvesting light energy by maximal oxidation and therefore open PSII reaction centres under ambient conditions of $\mathrm{CO}_{2}$ and saturating light, which can be monitored by observing the stability of steady-state fluorescence $\left(F_{\mathrm{s}}\right)$. If this stability is not achieved, the effective quantum yield of PSII ( $\left.\Phi_{\text {PSII }}\right)$ and subsequent calculations of important parameters such as the rate of electron transport based on the CF measurement $\left(J_{\mathrm{CF}}\right)$ could be underestimated. After all parameters had stabilized, the steady-state GE-derived parameters and several CF-derived parameters in the lightadapted state were recorded simultaneously. $F_{\mathrm{s}}$, followed shortly afterwards by the maximum fluorescence yield in the light-adapted state $\left(F_{\mathrm{m}}^{\prime}\right)$, was logged by the emission of a pulse of white light at $10000 \mathrm{mmol} \mathrm{m}^{-2} \mathrm{~s}^{-1}$ to close all PSII reaction centres, followed by a so-called "dark pulse" for measuring the minimal fluorescence $\left(F_{\mathrm{o}}^{\prime}\right)$ of a light-adapted leaf that has been momentarily darkened. The measurement of $\mathrm{CO}_{2}$ began after the completion of the preparation and acclimation, which required approximately $30 \mathrm{~min}$ in unstressed leaves and up to $2 \mathrm{~h}$ in stressed leaves.

\subsection{2 $\mathrm{CO}_{2}$ experiments}

The $\mathrm{CO}_{2}$-response curves were recorded at a $T_{\text {Leaf }}$ of $25^{\circ} \mathrm{C}$ and a quantum flux density of $1000 \mu \mathrm{mol}$ photons $\mathrm{m}^{-2} \mathrm{~s}^{-1}$. The values of $C_{\mathrm{a}}$ used to generate the response curves were $400 \rightarrow 300 \rightarrow 200 \rightarrow 150 \rightarrow 100 \rightarrow 50 \rightarrow 400 \rightarrow 400 \rightarrow 600$ $\rightarrow 800 \rightarrow 1200 \rightarrow 2000$ (in $\mu \mathrm{mol} \mathrm{CO}_{2} \mathrm{~m}^{-2} \mathrm{~s}^{-1}$ ). The minimum and maximum times for stabilizing $A_{\text {net }}, g_{\mathrm{s}}$, and $C_{\mathrm{i}}$ for each $\log$ were set to 4 and 6 min, respectively.

\subsubsection{Light experiments}

Light-response curves (A/PPFD) were generated at a $C_{\mathrm{a}}$ of $400 \mu \mathrm{mol} \mathrm{CO}_{2} \mathrm{~m}^{-2} \mathrm{~s}^{-1}$ by automatically applying changes in the photosynthetically active radiation with the LI-6400XT light source. To obtain precise responses at the low range of the light gradient for estimating the daily mitochondrial respiration by the Kok effect (Kok, 1948), we used the following PPFD sequence: $2500 \rightarrow 2000 \rightarrow 1500 \rightarrow 1000 \rightarrow 800 \rightarrow 600 \rightarrow 500 \rightarrow 400$ $\rightarrow 300 \rightarrow 200 \rightarrow 150 \rightarrow 125 \rightarrow 100 \rightarrow 75 \rightarrow 50 \rightarrow 40 \rightarrow 30$ $\rightarrow 20 \rightarrow 10 \rightarrow 5 \rightarrow 0$ (in $\mu$ mol photons $\mathrm{m}^{-2} \mathrm{~s}^{-1}$ ). The minimum and maximum times between each light level for the generation of the A/PPFD curves were set to 1 and 2 min, respectively. The gradient from high to low light during an A/PPFD curve led to a drop in $T_{\text {Leaf }}$ as the light decreased. The rapid changes in the light levels prevented the adjustment of $T_{\text {Leaf }}$ while guaranteeing stable air and water fluxes and avoiding noisy measurements of $C_{\mathrm{i}}$ and $g_{\mathrm{s}}$. We thus decided to maintain a stable Peltier-block temperature ( $\left.T_{\text {block }}\right)$ in the leaf cuvette. Hence, $T_{\text {block }}$ was first adjusted so that $T_{\text {Leaf }}$ was $25^{\circ} \mathrm{C}$ at the beginning of the A/PPFD curve and then kept stable throughout the experiment. $T_{\text {Leaf }}$ had dropped by approximately $1-3^{\circ} \mathrm{C}$ by the completion of the A/PPFD curve.

The calculation of the parameters NPQ, qP and temperature functions can be found in the supplementary material.

\subsection{Calculation of CF-derived parameters}

The maximum efficiency of PSII was calculated by:

$\frac{F_{\mathrm{v}}}{F_{\mathrm{m}}}=\frac{\left(F_{\mathrm{m}}-F_{\mathrm{o}}\right)}{F_{\mathrm{m}}}$,

where $F_{\mathrm{v}}$ is the variable fluorescence of a dark-adapted sample, $F_{\mathrm{m}}$ is the maximal fluorescence measured after a saturating light pulse, and $F_{\mathrm{o}}$ is the minimal fluorescence measured under darkness. These parameters were obtained from dark-adapted leaves with closed PSII reaction centres as described in the previous sections. The $F_{\mathrm{v}} / F_{\mathrm{m}}$ ratio describes the fraction of photochemically absorbed photons under dark 
conditions. Typical values range between 0.75 and 0.85 , depending on age, health and preconditioning. The $F_{\mathrm{v}} / F_{\mathrm{m}}$ ratio provides information about the maximum or optimum quantum yield and serves as an indicator of stress in the photosystems (Buschmann, 2007). Ratios below 0.80 are indicative of induced photoprotection and sustained energy dissipation (Maxwell and Johnson, 2000; Verhoeven, 2014), whereas leaves with ratios below 0.74 are considered to be below the recovery threshold (Björkman and Demmig, 1987). The effective quantum yield of PSII was estimated by

$\Phi_{\mathrm{PSII}}=\frac{\left(F_{\mathrm{m}}^{\prime}-F_{\mathrm{s}}\right)}{F_{\mathrm{m}}^{\prime}}$,

where $F_{\mathrm{s}}$ is the steady-state fluorescence in a fully lightadapted sample, and $F_{\mathrm{m}}^{\prime}$ is the maximal fluorescence yield after a pulse of high light. The $\Phi_{\text {PSII }}$ is the counterpart of the optimum quantum yield and represents the fraction of photochemically absorbed photons in a light-adapted leaf (Maxwell and Johnson, 2000):

$J_{\mathrm{CF}}=\varepsilon \times \Phi_{\mathrm{PSII}} \times \alpha_{\mathrm{L}}$,

where $\varepsilon$ is a scaling factor for the partitioning of intercepted light between photosystems I and II. We assumed that light was equally distributed between both photosystems $(\varepsilon=0.5)$ (Bernacchi et al., 2002; Niinemets et al., 2005). $\alpha_{\mathrm{L}}$ is the foliar absorbance determined in separate measurements of foliar reflectance and transmittance. The following values of $\alpha_{\mathrm{L}}$ were determined: 0.932 for $Q$. ilex and 0.912 for P. halepensis, with no differences between sunlit and shaded leaves of these two species, and 0.935 for sunlit leaves of A. unedo, and 0.917 for shaded leaves of $A$. unedo. For the determination of these leaf absorptances $\left(\alpha_{\mathrm{L}}\right)$, foliar reflectance and transmittance were measured at midday in August 2012 using a spectroradiometer UniSpec Spectral Analysis System (PP Systems, Haverhill, MA, USA). The value of $J_{\mathrm{CF}}$ at a $\mathrm{CO}_{2}$ concentration of $400 \mu \mathrm{mol} \mathrm{CO} \mathrm{m}^{-2} \mathrm{~s}^{-1}$ and a PPFD of $1000 \mu$ mol photons $\mathrm{m}^{-2} \mathrm{~s}^{-1}$ was termed ambient photosynthetic electron transport $\left(J_{\mathrm{amb}}\right)$. Its relationship with the net assimilation rate $\left(J_{\mathrm{amb}} / A_{\text {net }}\right)$ was used for the analyses of alternative electron sinks beside carbon metabolism.

\subsection{Estimation of light respiration and calculation of the effective quantum yield of $\mathrm{CO}_{2}\left(\Phi_{\mathrm{CO}_{2}}\right)$}

In the literature, the term $R_{\mathrm{d}}$ was sometimes used for dark respiration (Farquhar et al., 1980; Turnbull et al., 2003), but also for day respiration (Flexas et al., 2012; Yin et al., 2011). We will use $R_{\mathrm{d}}$ to represent mitochondrial respiration during the day or under lighted conditions and $R_{\mathrm{n}}$ to represent mitochondrial respiration at night or under darkadapted conditions. We estimated $R_{\mathrm{n}}$ during the day after darkening the leaf for at least $30 \mathrm{~min}$. $R_{\mathrm{d}}$ was estimated from the light-response curves with the combined GE and CF measurements proposed by Yin et al. (2009), named the CF method. This method amended the Kok method (Kok, 1948) by substituting the A/PPFD relationship with $\left.\mathrm{A} /\left(\mathrm{PPFD} \times \Phi_{\mathrm{PSII}} / 4\right)\right)$. See Yin et al. (2009) for details.

The effective quantum yield of $\mathrm{CO}_{2}\left(\Phi_{\mathrm{CO}_{2}}\right.$, unitless $)$ can be calculated using the estimated $\alpha_{\mathrm{L}}, R_{\mathrm{d}}$, together with $A_{\text {net }}$ and PPDF as follows:

$\Phi_{\mathrm{CO}_{2}}=\frac{\left(A_{\text {net }}-R_{\mathrm{d}}\right)}{\text { PPFD } \times \alpha_{\mathrm{L}}}$.

\subsection{The Farquhar, von Caemmerer and Berry photosynthesis model (FvCB)}

(1980)

The FvCB photosynthesis model was employed on the assumption that foliar carbon assimilation was limited either by Rubisco activity $\left(A_{\mathrm{c}}\right)$ or by ribulose-1,5-bisphosphate (RuBP) regeneration $\left(A_{\mathrm{j}}\right)$ and was driven by light, temperature, and $\mathrm{CO}_{2}$. The model was further complemented with a third limitation: the photosynthetic rate limited by triosephosphate use $\left(A_{\mathrm{p}}\right)$ (Sharkey, 1985). $A_{\text {net }}$ can then be determined by the minimum of these three potential rates from an $A / C_{\mathrm{c}}$ curve:

$A_{\text {net }}=\min \left\{A_{\mathrm{c}}, A_{\mathrm{j}}, A_{\mathrm{p}},\right\}$,

where

$A_{\mathrm{c}}=V_{\mathrm{c}, \max } \times\left[\frac{C_{\mathrm{c}}-\Gamma^{*}}{C_{\mathrm{c}}+K_{\mathrm{c}}\left(1+\frac{O}{K_{\mathrm{o}}}\right)}\right]-R_{\mathrm{d}}$,

where $V_{\mathrm{c}, \max }$ represents the maximum rate of Rubisco carboxylation, $K_{\mathrm{c}}$ is the Michaelis-Menten constant of Rubisco for $\mathrm{CO}_{2}, O$ is the partial pressure of $\mathrm{O}_{2}$ at Rubisco, and $K_{\mathrm{O}}$ is the Michaelis-Menten constant of Rubisco for $\mathrm{O}_{2}$ (Table B1, see Appendix B) and $C_{\mathrm{c}}$ determined with the variable-J method (Eqs. A7 and A8). The equation representing photosynthesis limited by RuBP regeneration is

$A_{j}=J *\left[\frac{C_{\mathrm{c}}-\Gamma^{*}}{4 C_{c}+8 \Gamma^{*}}\right]-R_{\mathrm{d}}$,

where $J$ is the rate of electron transport. The denominator of the above equation represents the stoichiometry of the number of electrons required to regenerate ATP and NADP; we have used four for $C_{\mathrm{c}}$ and eight for $\Gamma^{*}$ (Flexas et al., 2012). We assumed that $J$ becomes $J_{\max }$ under light and $\mathrm{CO}_{2}$ saturation when the maximum possible rate of electron transport is theoretically achieved (see also Buckley and Diaz-Espejo, 2014).

The photosynthetic rate limited by triose-phosphate use is estimated by

$A_{\mathrm{p}}=\frac{3 \mathrm{TPU} \times C_{\mathrm{c}}}{\Gamma^{*}\left[C_{\mathrm{c}}-\left(\frac{1+3 \alpha_{\mathrm{TPU}}}{2}\right)\right]}-R_{\mathrm{d}}$,

where TPU is the rate of triose-phosphate use at saturating $\mathrm{CO}_{2}$ concentrations, and $\alpha_{\mathrm{TPU}}$ is the proportion of glycerate 
not returned to the chloroplasts. This equation fits the $A / C_{\mathrm{c}}$ curve plateau at high concentrations of $\mathrm{CO}_{2}$ when a further increase in $C_{\mathrm{c}}$ no longer increases $A_{\text {net }}$ or, in some cases, decreases $A_{\text {net }}$.

These three estimated parameters $\left(V_{\mathrm{c}, \max }, J_{\max }\right.$ and TPU) define the biochemical capacity to drive the photosynthetic assimilation of $\mathrm{CO}_{2}$ but are defined here as the photosynthetic potential (Niinemets et al., 2006). The term photosynthetic capacity is here dismissed, despite its frequent use in the literature, to avoid confusion with studies that have used this term for the maximum rate of assimilation under saturating light conditions (e.g. Bertolli and Souza, 2013).

\subsection{Curve fitting}

The procedure for fitting the curves to estimate the photosynthetic parameters $V_{\mathrm{c}, \max }, J_{\max }$ and TPU applied the least square fit method using the SOLVER estimator tool in Excel. In this procedure, the squared errors of the observed points on the $A / C_{\mathrm{c}}$ curve and the modelled points of Eqs. (6)-(8) were calculated and summed. Prior to the fitting procedure, the user must assess the limiting factors, i.e. which points are allocated to which of Eqs. (6)-(8). The initial slope of the $A / C_{\mathrm{c}}$ curve is attributed to non-saturating $\mathrm{CO}_{2}$ conditions when Rubisco activity limits $A_{\text {net }}$ (Eq. 6), while the slope of the curve is smoothed at higher $\mathrm{CO}_{2}$ conditions (usually $>35 \mathrm{~Pa}$ ), representing the limitation of the regeneration of ribulose-1,5-biphosphate $(\mathrm{RuPb})$ (and hence light is a limiting factor) (Eq. 7). The transition zone (approximately at 25-35 Pa of $C_{\mathrm{i}}$ ), however, is a grey zone where one point can be attributed to either one or another limitation. These points can also introduce noise in the estimations in cases of doubt and are best discarded. Moreover, unusual points with evidence of an error during the measurements were not included in the curve-fitting procedure. At very high $\mathrm{CO}_{2}$ concentrations, the $A / C_{\mathrm{c}}$ curve plateaus or even decreases slightly. In this case, these points can be attributed to the limitation of triose-phosphate use (Eq. 8). The $\mathrm{CO}_{2}$ response curves, however, rarely exhibit such a plateau or decrease at high $\mathrm{CO}_{2}$ concentrations when working on a $C_{\mathrm{c}}$ rather than a $C_{\mathrm{i}}$ basis, so TPU could seldom be estimated in our study. Finally, when attributing all observed points to one or another limitation, we could then estimate the values of $V_{\mathrm{c}, \max }$ and $J_{\max }$ (and possibly TPU) with the SOLVER Excel tool, which iteratively changes the three parameters to minimize the sum of squares of deviation from the observation.

\subsection{Correction for diffusion leakage}

Large gradients between the ambient air and the $\mathrm{CO}_{2}$ concentrations inside the chamber are created during the generation of a carbon-response curve. This leakage is particularly important at the high and low ends of the carbon-response curve when a large $\mathrm{CO}_{2}$-concentration gradient exists between the leaf chamber and the surrounding ambient con-

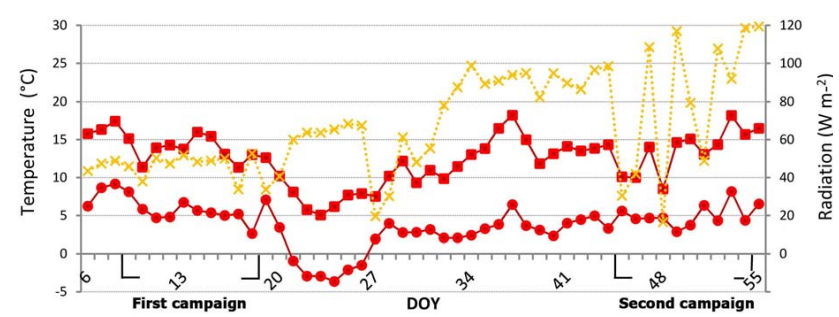

Figure 1. Maximum and minimum temperatures on the primary $y$ axes (in red squares and circles, respectively) and radiation (in yellow crosses) on the secondary $y$-axes are presented for the mild and frost winter period for the day of the year (DOY) in January and February 2012.

centration. Based on the findings by Flexas et al. (2007a), we corrected $A_{\text {net }}$ by subtracting the diffusion leakage for each step of the $A / C_{\mathrm{c}}$ curve obtained from separate response curves with leaves thermally killed in hot water.

\subsection{Statistical analyses}

All statistical analyses were performed using the $\mathrm{R}$ software package, version 3.0.2 (http://www.r-project.org/). Differences in the parameters between the mild and cold winters were determined with Student's $t$-tests $(P \leq 0.05)$. ShapiroWilk tests of normality tested for normality of the data. Data were normalized at $P \leq 0.1$. One-factorial analyses of variance (ANOVAs) with tree species as the main factor tested for differences between tree species of the parameters in the sampling periods. Significant differences were determined at $P \leq 0.05$ with Tukey's HSD tests. Regression analyses were conducted to study the relationship between $J_{\max }$ and $V_{\mathrm{c}, \max }$ and between $J_{\text {amb }}$ and $A_{\text {net }}$. Analyses of covariance (ANCOVAs) tested for differences in slopes and intercepts.

\section{Results}

\subsection{Environmental variables}

Collserola Natural Park experienced extremely mild winter conditions in November and December 2011 and January 2012 , when average minimum temperatures $\left(10.4^{\circ} \mathrm{C}\right.$ in November, $5^{\circ} \mathrm{C}$ in December, and $3.4^{\circ} \mathrm{C}$ in January) remained above $0^{\circ} \mathrm{C}$ and no frosts occurred. Average maximum temperatures were $16.3^{\circ} \mathrm{C}$ in November, $12.2^{\circ} \mathrm{C}$ in December, and $11.4^{\circ} \mathrm{C}$ in January. All species had considerable shoot growth of up to $15 \mathrm{~cm}$ during this mild period. Sudden low temperatures, however, led to frost on 6 consecutive days and a minimum average temperature of $-2.3{ }^{\circ} \mathrm{C}$ (day of the year, DOY 21-26) followed by 8 days of cool temperatures averaging $+2.6^{\circ} \mathrm{C}$ (DOY 27-35) (Fig. 1). The average radiation during first field campaign (DOY 9-19) was 46 and during the period of frost was $58 \mathrm{~W} \mathrm{~m}^{-2}$. 

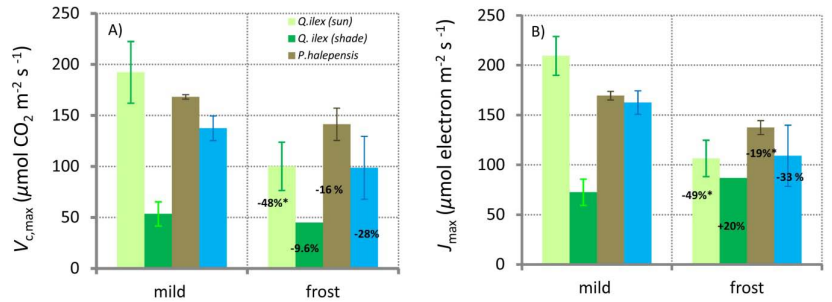

Figure 2. Bar plot of the effect of a sudden period of frost following a mild winter period in 2012 on (a) the maximum velocity of carboxylation $\left(V_{\mathrm{c}, \max }\right)$ and (b) the maximum rate of electron transport $\left(J_{\max }\right)$ in sunlit leaves of $Q$. ilex (light green bar), in shaded leaves of $Q$. ilex (dark green bar), P. halepensis (beige bar) and A. unedo (blue bar). The error bars represent the standard error, and the percentages indicate the change between periods where significance is indicated with an asterisk $(P \leq 0.05)$.
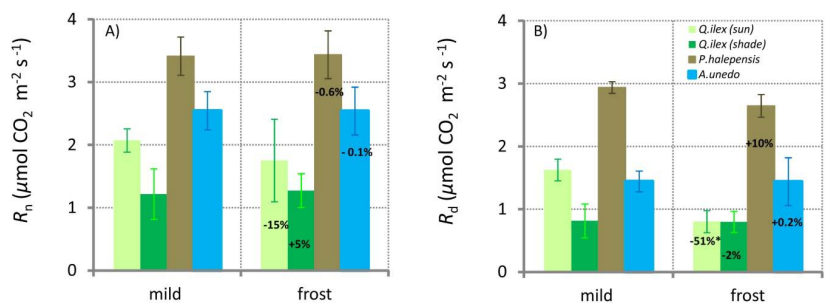

Figure 3. Bar plot of the effect of a sudden period of frost following a mild winter period on (a) nighttime respiration $\left(R_{\mathrm{n}}\right)$ and (b) daytime respiration $\left(R_{\mathrm{d}}\right)$ in sunlit leaves of $Q$. ilex (light green bar), in shaded leaves of $Q$. ilex (dark green bar), P. halepensis (beige bar) and $A$. unedo (blue bar). The error bars represent the standard error, and the percentages indicate the change between periods where significance is indicated with an asterisk $(P \leq 0.05)$.

\subsection{Photosynthetic potentials}

Of the three photosynthetic parameters describing the photosynthetic potential, $V_{c, \max }, J_{\max }$ and TPU, only the first two could be satisfactorily estimated from the $A / C_{\mathrm{c}}$-response curves. The leaves were only occasionally limited by TPU ( 6 out of 42), despite the excessive $\mathrm{CO}_{2}$ concentrations in the higher section of the $\mathrm{CO}_{2}$-response curve. TPU was therefore discarded from further analysis. $V_{\mathrm{c}, \max }$ and $J_{\max }$ were highest in $Q$. ilex but more importantly also decreased most strongly after the period of frost by nearly $50 \%(P \leq 0.05$; Fig. 2). The photosynthetic potential of $P$. halepensis was affected the least, reflected by moderate decreases in $V_{\mathrm{c}, \max }$ and $J_{\max }\left(16\right.$ and $19 \%$ ), which were not significant. $V_{\mathrm{c}, \max }$ and $J_{\max }$ were lowest in A. unedo during the mild winter period and decreased by approximately $33 \%$ after the period of frost. This decrease, however, was not significant, due to a large standard error.
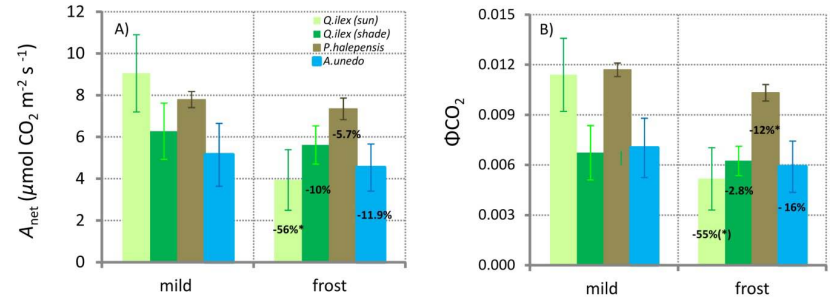

Figure 4. Bar plot of the effect of a sudden period of frost following a mild winter period on (a) net assimilation $\left(A_{\text {net }}\right)$ and (b) the effective quantum yield of net $\mathrm{CO}_{2}$ assimilation $\left(\Phi \mathrm{CO}_{2}\right)$ in sunlit leaves of $Q$. ilex (light green bar), in shaded leaves of $Q$. ilex (dark green bar), $P$. halepensis (beige bar) and $A$. unedo (blue bar). The error bars represent the standard error, and the percentages indicate the change between periods where significance is indicated with an asterisk $(P \leq 0.05)$ and marginal significance with an asterisk in parentheses $(0.05 \leq P \leq 0.1)$.
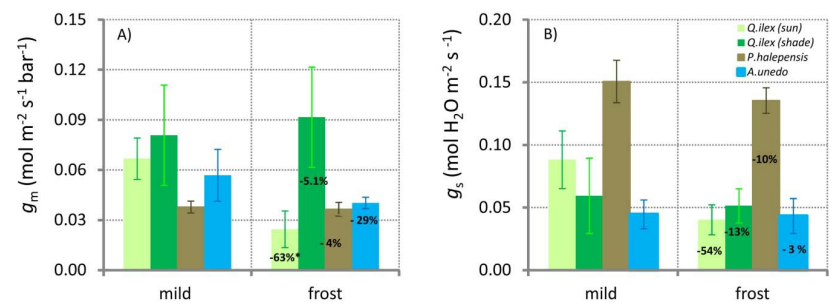

Figure 5. Bar plot of the effect of a sudden period of frost following a mild winter period on (a) mesophyllic conductance $\left(g_{\mathrm{m}}\right)$ and (b) stomatal conductance $\left(g_{\mathrm{s}}\right)$ in sunlit leaves of $Q$. ilex (light green bar), in shaded leaves of $Q$. ilex (dark green bar), $P$. halepensis (beige bar) and A. unedo (blue bar). The error bars represent the standard error, and the percentages indicate the change between periods where significance is indicated with an asterisk $(P \leq 0.05)$.

\subsection{GE-derived parameters under ambient conditions}

The period of frost had a strong effect on several GE-derived parameters in $Q$. ilex leaves. The cold temperatures decreased $R_{\mathrm{n}}$ in $Q$. ilex leaves, but the effect was much weaker than for $R_{\mathrm{d}}$ and was not significant (Fig. 3). These parameters responded very weakly to the cold and frost in the leaves of A. unedo and $P$. halepensis. $A_{\text {net }}$ and $\Phi_{\mathrm{CO}_{2}}$ were also reduced in $Q$. ilex leaves by approximately $50 \%$. This was significant for the $A_{\text {net }}$ (Fig. 4a) and of low significance for $\Phi_{\mathrm{CO}_{2}}$ (Fig. 4b). Further differences were only significant for $\Phi_{\mathrm{CO}_{2}}$ in $P$. halepensis leaves being reduced by $12 \%(P \leq 0.05)$. The $\mathrm{CO}_{2}$ conductance was more strongly reduced in $g_{\mathrm{m}}$ than in $g_{\mathrm{s}}$ for $Q$. ilex and A. unedo leaves which was only significant for the former whereas these parameters seemed unaffected in $P$. halepensis leaves (Fig. 5a and b). As a consequence, we observed a tendency of a $C_{\mathrm{i}}$ increase in parallel with a $C_{\mathrm{c}}$ decrease in $Q$. ilex and $A$. unedo leaves due to a lower $\mathrm{CO}_{2}$ uptake in carbon metabolism, but not in $P$. halepensis (Fig. 6a and b). The differences observed were not significant $(P \leq 0.05)$. 

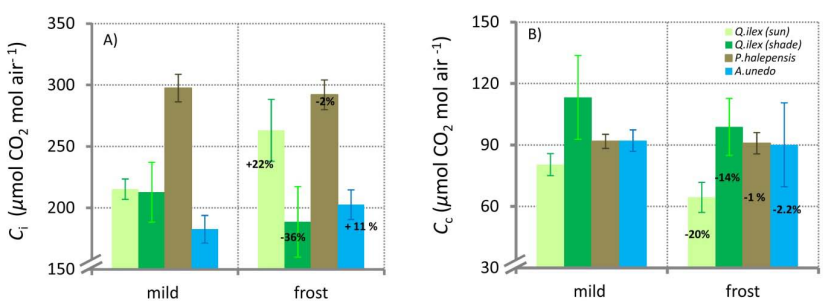

Figure 6. Bar plot of the effect of a sudden period of frost following a mild winter period on (a) the stomatal internal $\mathrm{CO}_{2}$ concentration $\left(C_{\mathrm{i}}\right)$ and $(\mathbf{b})$ the chloroplastic $\mathrm{CO}_{2}$ concentration $\left(C_{\mathrm{c}}\right)$ in sunlit leaves of $Q$. ilex (light green bar), in shaded leaves of $Q$. ilex (dark green bar), $P$. halepensis (beige bar) and A. unedo (blue bar). The error bars represent the standard error, and the percentages indicate the change between periods where significance is indicated with an asterisk $(P \leq 0.05)$.
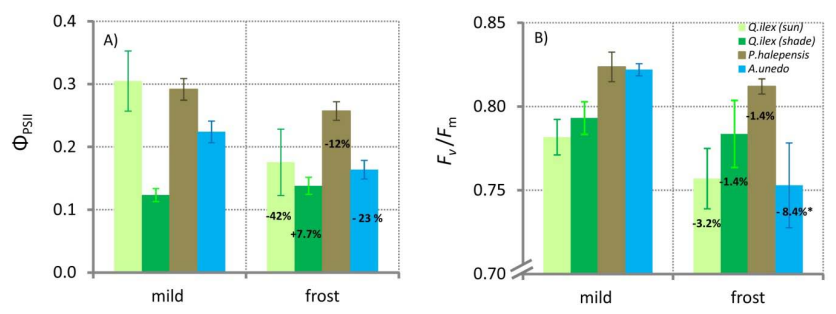

Figure 7. Bar plot of the effect of a sudden period of frost following a mild winter period on (a) the effective quantum yield of photosystem II ( $\left.\Phi_{\text {PSII }}\right)$ and (b) the maximum efficiency of photosystem II $\left(F_{\mathrm{V}} / F_{\mathrm{m}}\right)$ in sunlit leaves of $Q$. ilex (light green bar), in shaded leaves of $Q$. ilex (dark green bar), P. halepensis (beige bar) and A. unedo (blue bar). The error bars represent the standard error, and the percentages indicate the change between periods where significance is indicated with an asterisk $(P \leq 0.05)$.

\subsection{CF-derived parameters under ambient conditions}

The GE-derived parameters enabled us to study the immediate responses, but several CF-derived parameters allowed us to determine in more depth the physiological changes in parts of the light-harvesting apparatus, namely PSII. $F_{\mathrm{v}} / F_{\mathrm{m}}$ estimates the maximum quantum yield of PSII and serves as a stress indicator (Fig. 7b). A. unedo leaves were most strongly affected by the period of frost, followed by $Q$. ilex leaves, whereas $P$. halepensis leaves were only marginally affected. The changes were not statistically significant in the latter two species $(P \leq 0.05)$. $\Phi_{\text {PSII }}$ tended to decrease in all species but most strongly in $Q$. ilex leaves (42\%), however insignificantly (Fig. 7a). NPQ responded very differently in the three species. NPQ did not change much between the two sampling periods in the leaves of $P$. halepensis $(6 \%)$ but decreased significantly by $25 \%(0.05 \leq P \leq 0.1)$ in $A$. unedo leaves and tended to increase in $Q$. ilex leaves by $31 \%$ ( $P \geq 0.05)$, however insignificantly (Fig. 8).

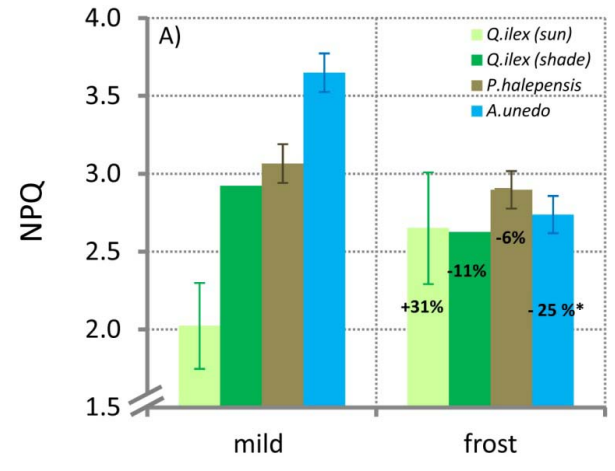

Figure 8. Bar plot of the effect of a sudden period of frost following a mild winter period on non-photochemical quenching (NPQ) in sunlit leaves of $Q$. ilex (light green bar), in shaded leaves of $Q$. ilex (dark green bar), P. halepensis (beige bar) and A. unedo (blue bar). The error bars represent the standard error, and the percentages indicate the change between periods where significance is indicated with an asterisk $(P \leq 0.05)$

\subsection{Relationships of foliar photosynthetic variables}

The covariance of several relationships of the foliar photosynthetic variables were analysed in an ANCOVA to test for differences in the slopes and intercepts in these relationships. The ANCOVA for the relationship between $V_{\mathrm{c}, \max }$ and $J_{\max }$ in $Q$. ilex leaves indicated a highly significant $(P \leq 0.01)$ reduction in the slope and also intercept showing a similar strong effect on $J_{\max }$ than on $V_{\mathrm{c}, \max }$ due to the change in weather (Fig. 9a and Table 2). In P. halepensis, the slope was significantly reduced and the intercept was marginally significantly reduced (Fig. 9b and Table 2). This shows a comparatively stronger effect on $V_{\mathrm{c}, \max }$ than on $J_{\max }$ by the cold period. The sunlit leaves of $A$. unedo and the shaded leaves of $Q$. ilex did not show any significant changes in the relationship of $V_{\mathrm{c}, \max }$ and $J_{\max }$ (Fig. 9a, c and Table 2). The relationship between the rate of electron transport at ambient conditions derived from $\mathrm{CF}$ and the $\mathrm{CO}_{2}$ assimilation at ambient $\mathrm{CO}_{2}$ concentrations $\left(J_{\mathrm{amb}} / A_{\text {net }}\right)$ was similar in all tree species (Fig. 10a, b, c and Table 2). The slopes were higher in response to the stress imposed by the low temperatures but were not significant. When all species were combined, the change of the slope was marginally significant, indicating a possible increased alternative electron sink other than carbon metabolism (Table 2).

\subsection{Role of leaf position}

Under mild conditions, the leaves of $Q$. ilex showed the most strongly pronounced differences in the leaf position (data of P. halepensis Mill. and A. unedo L., not shown). Leaves of $Q$. ilex growing under high irradiances had a more active carbon metabolism ( $A_{\text {net }}, R_{\mathrm{d}}, R_{\mathrm{n}}$, and $\left.\Phi_{\mathrm{CO}_{2}}\right)$, photochemical efficiency $\left(\Phi_{\mathrm{PSII}}\right)$, and photosynthetic potential (high $J_{\max }$ and $\left.V_{\mathrm{c}, \max }\right)$ in all tree species. As described in Sect. 2, the 
Table 1. $P$-values of Student's $t$-tests for the differences between sunlit and shaded leaves of $Q$. ilex.

\begin{tabular}{lrrr}
\hline & $\begin{array}{r}\text { Both } \\
\text { periods }\end{array}$ & $\begin{array}{r}\text { Mild } \\
\text { period }\end{array}$ & $\begin{array}{r}\text { Frost } \\
\text { period }\end{array}$ \\
\hline$V_{\mathrm{c}, \max }$ & 0.001 & 0.002 & 0.172 \\
$J_{\max }$ & 0.006 & 0.002 & 0.553 \\
$J_{\max } / V_{\mathrm{c}, \max }$ & 0.279 & 0.797 & 0.249 \\
$F_{\mathrm{V}} / F_{\mathrm{m}}$ & 0.611 & 0.533 & 0.535 \\
$A_{\text {net }}$ & 0.546 & 0.594 & 0.745 \\
$g_{\mathrm{s}}$ & 0.156 & 0.791 & 0.127 \\
$C_{\mathrm{i}}$ & 0.151 & 0.326 & 0.154 \\
$g_{\mathrm{m}}$ & 0.041 & 0.066 & 0.107 \\
$C_{\mathrm{c}}$ & 0.138 & 0.364 & 0.203 \\
$\mathrm{CUE}$ & 0.151 & 0.728 & 0.439 \\
$R_{\mathrm{n}}$ & 0.061 & 0.470 & 0.356 \\
$R_{\mathrm{d}}$ & 0.016 & 0.004 & 0.577 \\
$J_{\mathrm{amb}} / A_{\text {net }}$ & 0.052 & 0.014 & 0.203 \\
$\Phi_{\mathrm{PSI}}$ & 0.290 & 0.315 & 0.825 \\
$\Phi_{\mathrm{CO}}$ & 0.750 & 0.886 & 0.497 \\
$\mathrm{qP}$ & 0.195 & 0.045 & 0.882 \\
$\mathrm{NPQ}$ & 0.192 & 0.903 & 0.126 \\
$\Delta\left(C_{\mathrm{a}}-C_{\mathrm{i}}\right)$ & 0.037 & 0.321 & 0.068 \\
$\Delta\left(C_{\mathrm{i}}-C_{\mathrm{c}}\right)$ & 0.043 & 0.073 & 0.113 \\
$\Delta\left(C_{\mathrm{a}}-C_{\mathrm{c}}\right)$ & 0.023 & 0.006 & 0.122 \\
\hline & & &
\end{tabular}

effect of the leaf position after the sudden cold period was only studied for $Q$. ilex. After the sudden frost period, the photosynthetic potential was much higher in sunlit than in shaded leaves of $Q$. ilex, with both $J_{\max }$ and $V_{\mathrm{c}, \max }$ being highly significant (Fig. 2 and Table 1). These differences disappeared after the cold period, because $J_{\max }$ and $V_{\mathrm{c}, \max }$ in the shaded leaves remained unaffected by the frost. $F_{\mathrm{v}} / F_{\mathrm{m}}$ was generally higher in the shaded leaves, but not significantly $(P \leq 0.05)$ (Fig. 8 and Table 1). The photosynthetic parameters under ambient conditions, such as $A_{\text {net }}, g_{\mathrm{s}}, C_{\mathrm{i}}, C_{\mathrm{c}}$ and $g_{\mathrm{m}}$, were not affected much by the leaf position (Figs. 46 and Table 1). Although not significant, the effects of the cold period on these parameters were stronger in the sunlit leaves. In comparison to these parameters, the leaf position had more pronounced effects on $R_{\mathrm{n}}$ and $R_{\mathrm{d}}$ (Fig. 3 and Table 1). The response of respiration to winter stress, however, differed depending on the location of the leaves. $R_{\mathrm{n}}$ maintained the same balance between sunlit and shaded leaves before and after the cold period, but $R_{\mathrm{d}}$ decreased comparatively more in sunlit leaves due to the period of frost. This pattern was also reflected in $\Phi_{\mathrm{CO}_{2}}$ (Fig. $4 \mathrm{~b}$ and Table 1) and in the CF-derived parameters $\Phi_{\mathrm{PSII}}$ and NPQ, (Figs. 7a, 8 and Table 1) indicating a stronger effect on the photochemical machinery of sunlit leaves than on shaded leaves. Shaded leaves also exhibited a lower $J_{\mathrm{amb}} / A_{\text {net }}$ ratio, but the ratio increased equally in both leaf positions after the cold period, indicating a similar behaviour of dissipating energy by alternative electron sinks (Fig. 10a and Table 1).

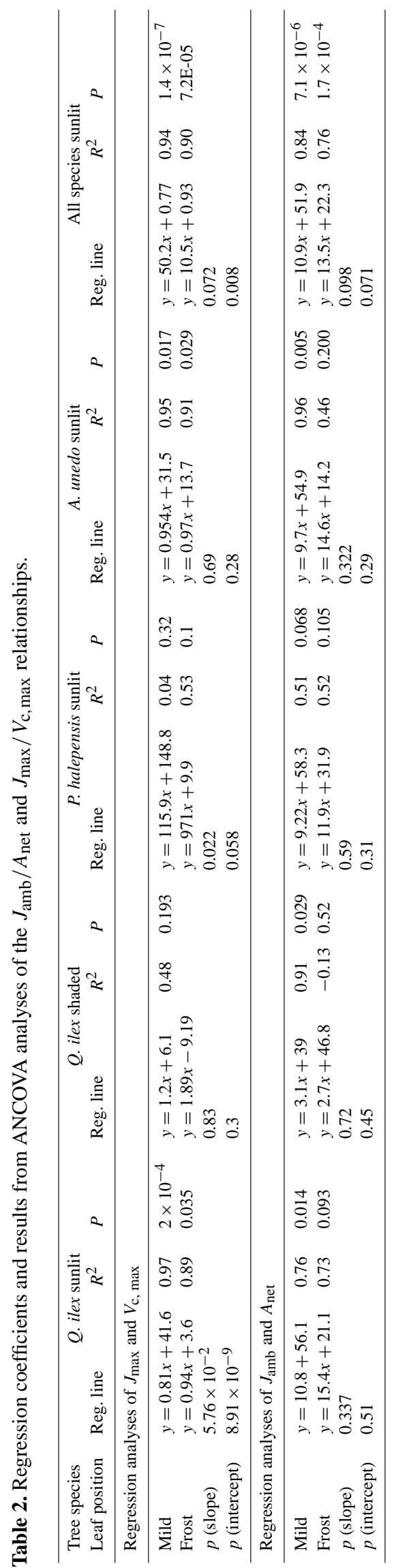

Biogeosciences, 11, 5657-5674, 2014 


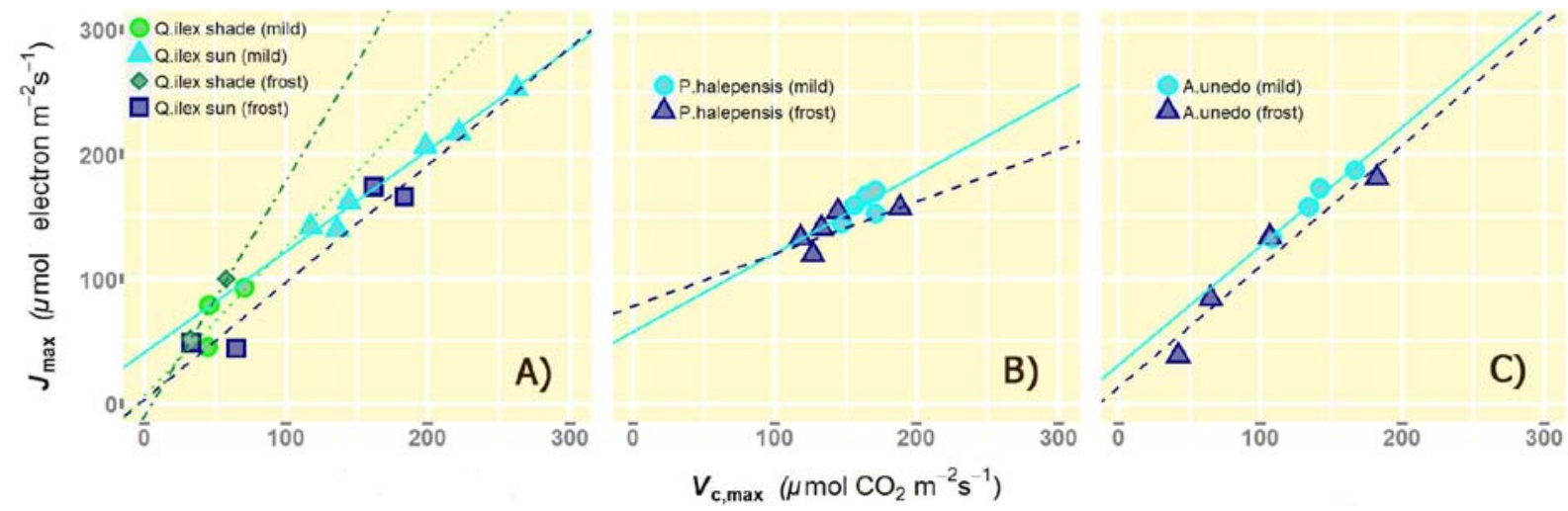

Figure 9. Relationship between the maximum velocity of carboxylation $\left(V_{\mathrm{c}, \max }\right)$ and the maximum rate of electron transport $\left(J_{\mathrm{max}}\right)$ in $(\mathbf{a})$ Q. ilex, (b) P. halepensis and (c) A. unedo leaves. Leaves measured under mild conditions are indicated by green circles and cyan triangles in shaded and sunlit locations, respectively. Leaves measured after the period of frost are indicated by green diamonds and blue squares in shaded and sunlit locations, respectively.
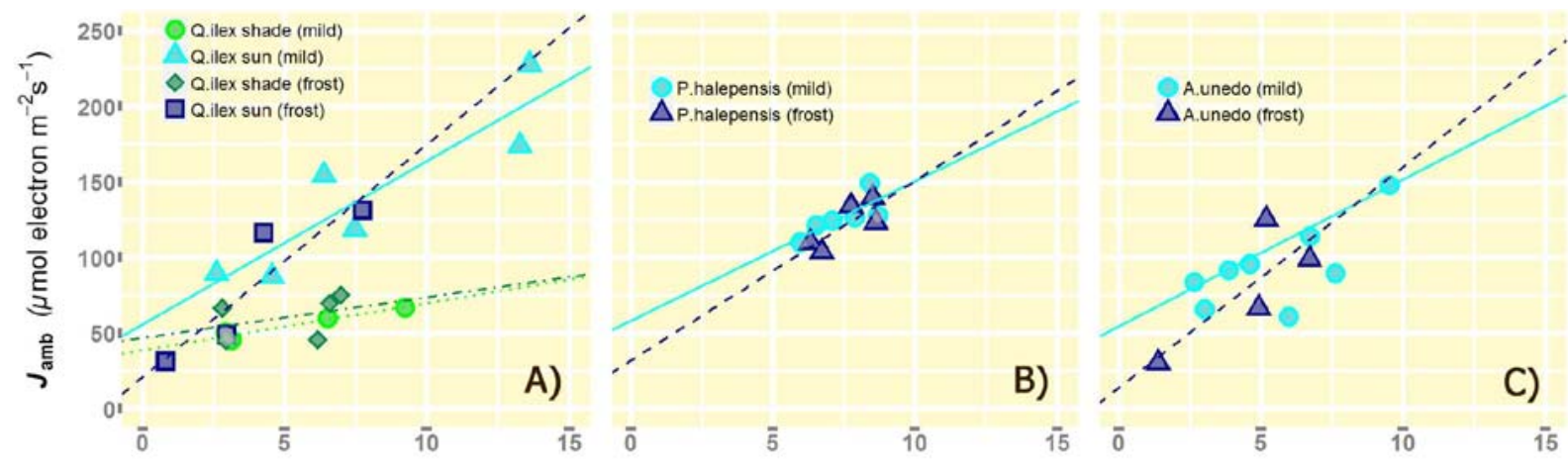

Figure 10. Relationship between the rate electron transport from chlorophyllic fluorescence $\left(J_{\mathrm{amb}}\right)$ and net assimilation $\left(A_{\text {net }}\right)$ at ambient $\mathrm{CO}_{2}$ concentrations and saturating light $\left(A_{\text {net }}\right)$ in (a) $Q$. ilex, (b) P. halepensis and (c) A. unedo leaves. Leaves measured under mild conditions are indicated by green circles and cyan triangles in shaded and sunlit locations, respectively. Leaves measured after the period of frost are indicated by green diamonds and blue squares in shaded and sunlit locations, respectively.

\section{Discussion}

\subsection{Winter in the Mediterranean region}

Mediterranean-type ecosystems are exposed to stress from summer droughts but also from low temperatures in winter (Mitrakos, 1980). Less attention, however, has been paid to the degree and extent as well as the wide variation among years and regions of these stress periods, in response to which Mediterranean evergreen species have developed a dynamic photoprotective ability in order to withstand these stressors (Kyparissis et al., 2000; Martínez-Ferri et al., 2004). Despite the occurrence of lower temperatures than in spring conditions, in winter the photosynthetic potential recovered once the leaves became acclimated to the new conditions (Dolman et al., 2002; Hurry et al., 2000). This is important for the plants' overall performance because the photosynthetic exploitation of favourable conditions in winter is crucial for achieving a positive carbon balance in Mediterranean evergreen tree species (García-Plazaola et al., 1999b; Martínez-Ferri et al., 2004). We showed how a long lasting comfortable winter period without frost lead to notably high photosynthetic potentials and carbon assimilation in winter being equal to or partly even exceeding spring values (Sperlich et al, unpublished data). As a result, increased winter temperatures influenced phenological responses, advanced winter cambium activation, spring bud burst and leaf unfolding which has been reported in an increasing number of studies (Peñuelas and Filella, 2001). These observations were also reflected in the high sap flow per tree $\left(J_{t}\right)$, ranging for all tree species on average between 5 and $10 \mathrm{~kg} \mathrm{~d}^{-1}$ during the mild winter period (Sánchez et al., unpublished results). Whereas sudden frosts have often been attributed to higher altitudes of the Mediterranean region (Blumler, 1991; Tretiach et al., 1997), we showed that it can also be an important factor for plant growth and distribution in other areas 
such as the sub-humid Mediterranean climate of our study site (Garcia-Plazaola et al., 2003a). At night when frosts are more likely to occur, we observed the lowest temperatures whereas at daytime the temperatures were often above zero degrees. However, as we showed, not only cool daytime but also cool nighttime temperatures or frosts can affect subsequent daytime photosynthesis and induce photoprotective processes (see also Flexas et al., 1999). In our study, the sudden occurring low temperatures affected strongly the photosynthetic apparatus, although the responses were highly species specific. We will elucidate the physiological mechanism in the following.

\subsection{PSII - primary target of stress induced by low temperatures}

Typically in winter there is an imbalance between light energy absorbed in photochemistry and light energy used in metabolism. This is shown in our data by increased thermal energy dissipation (NPQ) and reduced PSII efficiency $\left(\Phi_{\mathrm{PSII}}\right)$ in order to reduce the harmful effects of excess energy reflecting an inactivation and damage of PSII reaction centres - more precisely, the reaction-centre protein D1 (Aro et al., 1993; Demmig-Adams and Adams, 1992; Mulo et al., 2012). More precise information about the underlying processes that have altered this efficiency is provided by the $F_{\mathrm{v}} / F_{\mathrm{m}}$ ratio. Chronic changes occurring in the $F_{\mathrm{v}} / F_{\mathrm{m}}$ ratio can be related to a cascade of processes which are induced to protect the photosynthetic apparatus including (i) re-organization of the thylakoid membrane, (ii) closure of reaction centres, (iii) and/or reduced antennal size (Ensminger et al., 2012; Huner et al., 1998; Maxwell and Johnson, 2000; Verhoeven, 2014). The small changes in the $F_{\mathrm{v}} / F_{\mathrm{m}}$ ratio observed in the leaves of $Q$. ilex and $P$. halepensis reflected photoprotective responses without any photodamage. The significant decline of $F_{\mathrm{v}} / F_{\mathrm{m}}$ in $A$. unedo, however, indicated strong chronic photoinhibition and is an indication of severe photodamage (Martínez-Ferri et al., 2004). We conclude that $A$. unedo suffered most notably from the low temperatures whereas $Q$. ilex and $P$. halepensis were equipped with a good photoprotective capacity able to keep the photosynthetic apparatus intact (Öquist and Huner, 2003). Q. ilex showed the most dynamic responses, negating the harmful excitation stress by lowering the photochemical operating efficiency $\left(\Phi_{\mathrm{PSII}}\right)$ and increasing the use of alternative thermal-energy pathways (NPQ). This photoprotective capability represented by a higher NPQ is usually linked to the xanthophyll cycle that responds to environmental factors such as temperature, water deficit and nutrient availability (Demmig-Adams and Adams, 1996; García-Plazaola et al., 1997). Inter-conversions of the cycle and pool sizes occur following the need to dissipate excess excitation energy in response to summer drought (García-Plazaola et al., 1997; Munné-Bosch and Peñuelas, 2004), but also to winter stress (Corcuera et al., 2004; Garcia-Plazaola et al., 2003a; Ky- parissis et al., 2000; Oliveira and Penuelas, 2001). The implicit interpretation of being equipped with a high capacity of photoprotection when NPQ increases was recently questioned by Lambrev et al. (2012). This study reported that quenching and photoprotection were not necessarily linearly related and stated that several possibilities of photoprotective responses other than NPQ of CF existed, such as antennal detachment that could possibly vary with species and growth conditions. The highly dynamic and photoprotective capability of $Q$. ilex leaves, however, was also demonstrated by several other photosynthetic parameters such as $V_{\mathrm{c}, \max }, J_{\max }$, $A_{\text {net }}, \Phi_{\mathrm{CO}_{2}}$ and $R_{\mathrm{d}}$, which confirmed this trend and were in accord with the findings by Corcuera et al. (2004). Despite reports of several mechanisms of resistance to drought stress in A. unedo, including increased levels of zeaxanthin that indicates an enhanced thermal dissipation of excess excitation energy in periods of summer stress (Munné-Bosch and Peñuelas, 2004), we found that A. unedo leaves had a lower capacity of photoprotection in response to induced over-excitation of the photosystems by winter stress.

\subsection{High photosynthetic potentials and strong effects of low temperatures}

$V_{\mathrm{c}, \max }$ and $J_{\max }$ were strongly correlated (Wullschleger, 1993), being regulated in a coordinated manner above all in $Q$. ilex. Interestingly, the ANCOVAs indicated that $J_{\max }$ decreased more strongly than $\operatorname{did} V_{\mathrm{c}, \max }$. This is because the above-described photoprotective adjustments led to a lower energy-use efficiency in the reaction centres and consequently also to a downregulation of the photosynthetic electron transport $J_{\max }$. The larger decrease of $J_{\max }$ relative to $V_{\mathrm{c}, \max }$ indicated that low temperature stress became manifest first in a hampered pathway of photochemical energy, because PSII complexes are primarily affected by light-induced damage (Maxwell and Johnson, 2000; Taz and Zeiger, 2010; Vass, 2012). Hence, the limitations of the photosynthetic rate by RuBP regeneration are stronger affected by frost and cold induced stress than those by RuBP carboxylation. The relative amounts of photosynthetic proteins can probably explain the differences observed in the $J_{\max } / V_{\mathrm{c} \text {, max }}$ ratio (Hikosaka et al., 1999; Onoda et al., 2005).

The physiological responses were highly species specific. $Q$. ilex leaves responded with significant decreases (approximately $50 \%$ ) in their photosynthetic potentials (both $V_{\mathrm{c}, \max }$ and $\left.J_{\max }\right)$. In contrast, $V_{\mathrm{c}, \max }$ and $J_{\max }$ decreased in $P$. halepensis leaves by only 16 and $19 \%$, respectively, and in A. unedo leaves by approximately $30 \%$ (for both parameters). 


\subsection{Inhibition of carbohydrate metabolism}

As demonstrated above, adjustments to the frost event took place via the energy flow in the antennal systems and a downregulation of photosynthetic electron transport as well as regulatory mechanisms including the inhibition of $\mathrm{Ru}-$ bisco activity, but also via stomatal and mesophyllic diffusion behaviour (Ensminger et al., 2012; Gratani et al., 2000; Taz and Zeiger, 2010). Interestingly, the mesophyllic diffusion resistance was stronger pronounced as a response to low temperatures, especially in $Q$. ilex reducing the $\mathrm{CO}_{2}$ available for fixation in the chloroplasts. This underlines the recently growing awareness in the scientific community about the important role of $g_{\mathrm{m}}$ as an additional regulating parameter as response to stress, above all in sclerophyllic species (Flexas et al., 2008; Niinemets et al., 2011). In general, our results demonstrated that the efficiency of carbon use in the photosynthetic metabolism and foliar respiratory responses were highly species dependant (Zaragoza-Castells et al. 2007, 2008). For instance, $P$. halepensis and $Q$. ilex leaves depicted extraordinarily high values of $A_{\text {net }}, R_{\mathrm{d}}, R_{\mathrm{n}}$ and $\Phi_{\mathrm{CO}_{2}}$ in the mild winter period, but only $Q$. ilex exhibited a significant downregulation after the frost event. The downregulation of photosynthesis, the most efficient process to get rid of excess energy, suggests alternative energy pathways such as photorespiration. We did not measure photorespiration directly, but we could infer some of its characteristics by studying the relationship between $J_{\mathrm{amb}}$ and $A_{\text {net }}$. All tree species had a relatively higher proportion of electron flux during the period that can be explained by utilization in the carbon metabolism. This has been mainly attributed to photorespiration, but also to the Mehler reaction that protects plants from photodamage in bright light (Allen and Ort, 2001; D'Ambrosio et al., 2006; Flexas et al., 1998, 1999; Fryer et al., 1998; Huner et al., 1998).

\subsection{Leaf position specific responses to abiotic stress in winter}

It is well known that leaves growing under high irradiances have a more active carbon metabolism ( $A_{\text {net }}, R_{\mathrm{d}}, R_{\mathrm{n}}$ and $\Phi_{\mathrm{CO}_{2}}$ ), photochemical efficiency ( $\left.\Phi_{\mathrm{PSII}}\right)$, and photosynthetic potential (high $J_{\max }$ and $V_{\mathrm{c}, \max }$ ) (Taz and Zeiger, 2010). In this regard, $Q$. ilex showed the most strongly pronounced differences between sunlit and shaded leaves. Plants develop leaves with a highly specialized anatomy and morphology for the absorption of the prevailing light in their local environments resulting generally in smaller but also thicker sunlit leaves (Kull and Niinemets, 1993; Terashima and Hikosaka, 1995). Nevertheless, the higher carbon metabolism and photochemical activity of sunlit leaves decreased strongly, partly below the level of shaded leaves, whereas shaded leaves showed little sign of any downregulation but maintained a relatively stable effective quantum yield of $\mathrm{CO}_{2}$ assimilation in both periods. Furthermore, the photosystems showed no sign of photodamage and generally maintained a higher maximum efficiency than did sunlit leaves. We concluded that foliar-level physiology during winter was better protected in the shaded crown of $Q$. ilex unexposed to the dramatic changes in radiation in the outer canopy, confirming the results by Valladares et al. (2008). We also concluded that $Q$. ilex is a highly dynamic species able to rapidly change its metabolism on the antioxidant and photoprotective level in dependence to its leaf position (García-Plazaola et al., 1997, 1999a; Martínez-Ferri et al., 2004). We show that the foliar plasticity in morphology and anatomy of $Q$. ilex (Bussotti et al., 2002; Valladares et al., 2000) can also be attributed to its biochemical metabolism. We stress that the solar environment of the leaves is a crucial factor when assessing tree performance, especially when comparing tree species in a competitive context.

\subsection{Ecological context}

$Q$. ilex had the most drastic photoprotective response to frost and cool temperatures, whereas $P$. halepensis exhibited a homeostatic behaviour with a very active carbon assimilatory and respiratory metabolism in both periods. A. unedo was intermediate, with large decreases in the parameters of carbon metabolism but also a high variability in its response to frost. A. unedo also had the lowest photoprotective capability, which might be explained by previous characterisations to be semi-deciduous to drought being at the borderline to evergreen sclerophyllous species (Gratani and Ghia, 2002a, 2002b). Moreover, A. unedo occurs naturally most commonly as a shrub and is less frequently found in the forest canopy of mixed forests growing up to 8-10 $\mathrm{m}$ tall as in our study site (Beyschlag et al., 1986; Reichstein et al., 2002). Investments in leaves are thus lower and leaf longevity shorter. Leaves of $A$. unedo are more rapidly replaced relative to more sclerophyllic leaves such as those of $Q$. ilex. We postulated that A. unedo, considered a relict of the humidsubtropical Tertiary tree flora, was more sensitive to winter stress, which is consistent with its presence mostly in the western Mediterranean basin and its frequent occurrence in coastal zones where humidity and temperature are the main factors determining its geographical distribution (Gratani and Ghia, 2002a and references therein). Our results suggested that $Q$. ilex could greatly benefit from favourable winter conditions exhibiting a high photosynthetic potential and carbon metabolism. Angiosperms are known to make efficient use of favourable winter periods to recover depleted carbon reserves and embolism-induced loss of hydraulic capacity (Carnicer et al., 2013 and references therein). When these relatively favourable conditions changed, $Q$. ilex quickly re-adjusted the photosynthetic machinery to the prevailing conditions, as indicated by the largest decreases in photosynthetic potential and carbon metabolism. Some researchers have proposed the lutein-epoxy cycle in photoprotection of Quercus as a mechanism to maintain sustained energy dissipation 
(Garcia-Plazaola et al., 2003b), which could help to account for the higher tolerance to low temperatures in $Q$. ilex relative to other co-occurring Mediterranean trees or shrubs (Ogaya and Peñuelas, 2003, 2007). P. halepensis did not suffer a pronounced chronic photoinhibition, confirming the results by Martínez-Ferri et al. (2004). Despite a pronounced downregulation of photosynthetic electron transport and an increase in alternative electron sinks, the light-saturated ambient photosynthesis and stomatal conductance remained surprisingly high and constant. P. halepensis thus exhibited a successful refinement of photosynthetic electron flow and possibly a successful repair of protein D1 in the PSII reaction centre. The strong downregulation in $Q$. ilex and the homogeneous response of $P$. halepensis were possibly due to distinct, previously described strategies. $Q$. ilex has been characterized as a photoinhibition-avoiding species and $P$. halepensis as a photoinhibition-tolerant species (Martinez-Ferri et al., 2000). We have extended this categorization for A. unedo, a less photoinhibition-tolerant tree species, which favoured carbon metabolic processes at the cost of chronic photoinhibition and photodamage. This strategy is similar to those in other semi-deciduous shrubs (Oliveira and Penuelas, 2001; Oliveira and Peñuelas, 2004). The physiological responses of $Q$. ilex, a slowly growing late-successional species, to environmental stressors are highly plastic (Zavala et al., 2000) due to its vegetative activity in a wide range of temperatures and high stomatal control in stressful conditions (Gratani et al., 2000; Savé et al., 1999), high plasticity index and resprouting dynamics (Espelta et al., 1999; Gratani et al., 2000), deep rooting system and large carbohydrate pools (Canadell and Lopez-Soria, 1998; Canadell et al., 1999), and high adaptive variability in foliar phenomorphology (Sabaté et al., 1999). Our findings showed the intra-crown variability in $Q$. ilex, where shaded leaves were widely unaffected by the inhibitory cold stress (Oliveira and Penuelas, 2001). The ability of $Q$. ilex to perform rapid metabolic changes in the antioxidant and photoprotective mechanisms could be of adaptive importance (García-Plazaola et al., 1999a). In contrast, $P$. halepensis is a fast growing conifer that quickly occupies open spaces after disturbances such as fires (Zavala et al., 2000). P. halepensis, as do all pines, has a low ability to store carbohydrates and therefore follows a strategy of water conservation and embolism avoidance (Meinzer et al., 2009). High rates of photosynthesis and growth require high concentrations of carboxylation enzymes in the carbon cycle that have high maintenance costs (Valladares and Niinemets, 2008), perhaps accounting for the high respiration rates found in $P$. halepensis leaves. Moreover, differences among the species are also likely to be the result of distinct foliar morphologies and crown architectures. Pine trees are characterized by a relatively low exposure of foliar surface area to direct sunlight due to the cylindrical shape and steep angles of their needles but at the same time are able to exploit a wider range of incident light angles than broadleaved trees. Despite reported flexible adjustments in the orienta- tion of the leaves in several Mediterranean broadleaved sclerophyllic species (Oliveira and Peñuelas, 2000; Vaz et al., 2011; Werner et al., 2002), needle leaves probably still confer some benefits to attain near-saturated photosynthetic rates over a wider range of diurnal and seasonal variation in sun angles (Jordan and Smith, 1993; Lusk et al., 2003), while at the same time showing a high tolerance to photoinhibition. This might account for the good performance of $P$. halepensis under mild winter conditions with moderate abiotic stresses such as in our study. However, under more severe and reoccurring frost events, $P$. halepensis might reach the threshold of its tolerance and severe frost damage can occur. This explains also its absence in mountain regions with more severe winters where $Q$. ilex becomes more competitive. Despite following distinct physiological strategies, both $Q$. ilex and $P$. halepensis seem to cope equally well with the winter conditions they were exposed to whereas the foliar photosynthetic systems of $A$. unedo were more sensitive to sudden frost impacts. Thus, $A$. unedo might have been in a competitive disadvantage for the following growing season.

Overall, we conclude that the photosynthetic exploitation of relatively favorable winter conditions might be crucial for evergreen Mediterranean tree species for achieving a positive annual carbon balance. The winter period might give important insights helping to explain the dynamics of Mediterranean forest communities when withstanding increased novel environmental conditions projected in multiple climate change scenarios and benefitting from periods of potential recovery and growth in winter. 


\section{Appendix A}

\section{A1 Temperature functions}

The effective Michaelis-Menten constants $K_{\mathrm{c}}$ and $K_{\mathrm{o}}$ and the photorespiratory compensation point, $\Gamma^{*}$, were taken from (Bernacchi et al., 2002) and are summarized in Table 3. The following generic temperature response functions were used to adjust these parameters to the prevailing $T_{\text {Leaf }}$ during the experiments:

$K_{\mathrm{c}}=e^{\left(c-\left(\frac{\Delta \mathrm{Ha}}{R \times\left(273.15+T_{\mathrm{L}}\right)}\right)\right)}$

$K_{\mathrm{O}}=e^{\left(c-\left(\frac{\Delta \mathrm{Ha}}{R \times\left(273.15+T_{\mathrm{L}}\right)}\right)\right)}$

$\Gamma^{*}=e^{\left(c-\left(\frac{\Delta H a}{R \times\left(273.15+T_{\mathrm{L}}\right)}\right)\right)} \times \frac{\mathrm{O}_{2}}{20.9}$,

where $R$ is a unitless gas constant (0.008314), $c$ is a scaling constant, $\Delta \mathrm{Ha}$ represents the activation energy and $\mathrm{O}_{2}$ is the oxygen concentration of the ambient air assumed to be 20.9 $\mathrm{kPa}$.

\section{A2 CF parameters}

The non-photochemical quenching (NPQ) was estimated by both dark- and light-adapted fluorescent signals $F_{\mathrm{m}}$ and $F_{\mathrm{m}}^{\prime}$ by

$\mathrm{NPQ}=\frac{\left(F_{\mathrm{m}}-F_{\mathrm{m}}^{\prime}\right)}{F_{\mathrm{m}}^{\prime}}$,

where $F_{\mathrm{m}}$ is the maximal fluorescence measured on a dark adapted leaf after a saturating light pulse and $F_{\mathrm{m}}^{\prime}$ is the maximal fluorescence yield of a light adapted leaf after a pulse of high light. Photochemical quenching (qP) indicates the proportion of open PSII reaction centres and tends to be highest in low light when leaves use light most efficiently (Maxwell and Johnson, 2000). qP was estimated by

$\mathrm{qP}=\frac{F_{\mathrm{m}}^{\prime}-F_{\mathrm{s}}}{F_{\mathrm{m}}^{\prime}-F_{\mathrm{o}}^{\prime}}$,

where $F_{\mathrm{o}}^{\prime}$ is the minimum fluorescence in a light-adapted leaf after a pulse of darkness and $F_{\mathrm{S}}$ is the steady-state fluorescence in a fully light-adapted sample.

\section{A3 Estimation of mesophyll conductance}

The $\mathrm{CO}_{2}$ pathway leads from the atmosphere to the intercellular air spaces through the stomata and from there diffuses through the air spaces of the mesophyll, cell walls, cytosol and chloroplastic envelopes and finally reaches the sites of $\mathrm{CO}_{2}$ fixation in the chloroplastic stroma where it is fixed by ribulose-1,5-bisphosphate carboxylase/oxygenase (Rubisco). In this study, we call this pathway the internal mesophyll diffusion conductance $\left(g_{\mathrm{m}}\right)$ and estimate it with the variable- $J$ method of Harley et al. (1992):

$g_{\mathrm{m}}=\frac{A_{\text {net }}}{C_{\mathrm{i}}-\frac{\left[\Gamma^{*} \times J_{\mathrm{CF}}+8\left(A_{\text {net }}+R_{\mathrm{d}}\right)\right]}{J_{\mathrm{CF}}-4\left(A_{\text {net }}+R_{\mathrm{d}}\right)}}$,

where $\Gamma^{*}$ is the $\mathrm{CO}_{2}$ concentration at which the photorespiratory efflux of $\mathrm{CO}_{2}$ equals the rate of photosynthetic uptake of $\mathrm{CO}_{2}$ (Table 3). Similarly to $g_{\mathrm{s}}, g_{\mathrm{m}}$ is defined as a unitless molar fraction, rendering the units for conductance the same as those for photosynthesis. Nonetheless, the drawdown of $\mathrm{CO}_{2}$ from the intercellular airspaces to the sites of carboxylation is thought to be dominated by the liquid phase of the chloroplast and is hence dependent on the partial pressure of the gas according to Henry's law (Harley et al., 1992). The units for conductance $\left(\mathrm{mol} \mathrm{m}^{-2} \mathrm{~s}^{-1} \mathrm{bar}^{-1}\right)$ are thus directly comparable to $g_{\mathrm{s}}$ when the atmospheric pressure is $1 \mathrm{bar}$. We assumed normal pressure (1.01325 bar) in our experiments that were conducted in Barcelona (Spain), which is close to sea level. The variable- $J$ method accounts for the variation in $g_{\mathrm{m}}$ with $C_{\mathrm{i}}$ and provides more accurate estimates of photosynthetic parameters than do $A / C_{\mathrm{c}}$ curves that assume a constant $g_{\mathrm{m}}$, especially during episodes of water stress (Flexas et al., 2007). The chloroplastic $\mathrm{CO}_{2}$ concentration can then be determined using $C_{\mathrm{i}}, A_{\text {net }}$ and $g_{\mathrm{m}}$ :

$C_{\mathrm{c}}=C_{\mathrm{i}}-\frac{A_{\text {net }}}{g_{\mathrm{m}}}$,

where $C_{\mathrm{c}}$ is the chloroplastic $\mathrm{CO}_{2}$ concentration.

\section{Appendix B}

Table B1. The scaling constant $(c)$ and energies of activation $(\Delta \mathrm{Ha})$ describing the temperature responses for Rubisco enzyme kinetic parameters $K_{\mathrm{C}}, K_{\mathrm{O}}$ and $\Gamma^{*}$. Taken from Bernacchi et al. (2002).

\begin{tabular}{rrrrl}
\hline & $25^{\circ} \mathrm{C}$ & $c$ & $\Delta \mathrm{Ha}$ & Unit \\
\hline$K_{\mathrm{c}}$ & 27.24 & 35.98 & 80.99 & $\mathrm{~Pa}$ \\
$K_{\mathrm{O}}$ & 16.58 & 12.38 & 23.72 & $\mathrm{kPa}$ \\
$\Gamma^{*}$ & 3.74 & 11.19 & 24.46 & $\mathrm{~Pa}$ \\
\hline
\end{tabular}


Acknowledgements. We thank Elisenda Sánchez for her assistance in the field work. The research leading to these results has received funding from the European Community's Seventh Framework Programme GREENCYCLESII (FP7 2007-2013) under grant agreement no. 238366 and also from the Ministerio de Economica y Competividad under grant agreement no. CGL2011-30590-C02-01 with the project name MED_FORESTREAM.

Edited by: V. Brovkin

\section{References}

Allen, D. J. and Ort, D. R.: Impacts of chilling temperatures on photosynthesis in warm-climate plants, Trends Plant Sci., 6, 3642, 2001.

Aro, E. M., Virgin, I., and Andersson, B.: Photoinhibition of photosystem, II. Inactivation, protein damage and turnover, Biochim. Biophys. Acta-Bioenerg., 1143, 113-134, 1993.

Aschmann, H.: Distribution and Peculiarity of Mediterranean Ecosystems, in: Mediterranean Type Ecosystems, vol. 7, edited by: Castri, F. and Mooney, H. A., Springer Berlin Heidelberg, Berlin, Heidelberg, 11-19, 1973.

Bernacchi, C. J., Portis, A. R., Nakano, H., Caemmerer, S. Von and Long, S. P.: Temperature response of mesophyll conductance, implications for the determination of rubisco enzyme kinetics and for limitations to photosynthesis in vivo, Plant Physiol., 130, 1992-1998, doi:10.1104/pp.008250.water, 2002.

Bertolli, S. C. and Souza, G. M.: The level of environmental noise affects the physiological performance of Glycine max under water deficit, Theor. Exp. Plant Physiol., 25, 36-45, 2013.

Beyschlag, W., Lange, O. L., and Tenhunen, J. D.: Photosynthesis und Wasserhaushalt der immergrünen mediterranen Hartlaubpflanze Arbutus unedo L. im Jahresverlauf am Freilandstandort in Portugal I. Tagesläufe von $\mathrm{CO}_{2}$-Gaswechsel und Transpiration unter natürlichen Bedingungen, Flora, 178, 409-444, 1986.

Björkman, O. and Demmig, B.: Photon yield of $\mathrm{O} 2$ evolution and chlorophyll fluorescence characteristics at $77 \mathrm{~K}$ among vascular plants of diverse origins, Planta, 170, 489-504, 1987.

Blumler, M. A.: Winter-deciduous versus evergreen habit in mediterranean regions?: a model, USDA For. Serv. Gen. Tech. Rep PSW-126, 194-197, 1991.

Buckley, T. N. and Diaz-Espejo, A.: Reporting estimates of maximum potential electron transport rate, New Phytol., doi:10.1111/nph.13018, 2014.

Buschmann, C.: Variability and application of the chlorophyll fluorescence emission ratio red/far-red of leaves, Photosynth. Res., 92, 261-71, doi:10.1007/s11120-007-9187-8, 2007.

Bussotti, F., Bettini, D., Grossoni, P., Mansuino, S., Nibbi, R., Soda, C., and Tani, C.: Structural and functional traits of Quercus ilex in response to water availability, Eviron. Exp. Bot., 47, 11-23, 2002.

Canadell, J. and Lopez-Soria, L.: Lignotuber reserves support regrowth following clipping of two Mediterranean shrubs, Funct. Ecol., 12, 31-38, doi:10.1046/j.1365-2435.1998.00154.x, 1998.

Canadell, J., Djema, A., López, B., Lloret, F., Sabaté, S., Siscart, D., and Gracia, C. A.: Structure and dynamics of the root system, in: Ecology of Mediterranean Evergreen Oak Forests, edited by:
Rodà, F., Retana, J., Gracia, C. A., and Bellot, J., Springer Berlin, Heidelberg, 47-59, 1999.

Carnicer, J., Barbeta, A., Sperlich, D., Coll, M., and Peñuelas, J.: Contrasting trait syndromes in angiosperms and conifers are associated with different responses of tree growth to temperature on a large scale, Front. Plant Sci., 4, 409, doi:10.3389/fpls.2013.00409, 2013.

Corcuera, L., Morales, F., Abadia, A., and Gil-Pelegrin, E.: The effect of low temperatures on the photosynthetic apparatus of Quercus ilex subsp. ballota at its lower and upper altitudinal limits in the Iberian peninsula and during a single freezing-thawing cycle, Trees, 19, 99-108, doi:10.1007/s00468-004-0368-1, 2004.

Cowling, R. M., Rundel, P. W., Lamont, B. B., Arroyo, M. K., and Arianoutsou, M.: Plant diversity in Mediterranean-climate regions, Trends Ecol. Evol., 11, 362-366, 1996.

D'Ambrosio, N., Arena, C., and De Santo, A. V.: Temperature response of photosynthesis, excitation energy dissipation and alternative electron sinks to carbon assimilation in Beta vulgaris L., Environ. Exp. Bot., 55, 248-257, doi:10.1016/j.envexpbot.2004.11.006, 2006.

Demmig-Adams, B. and Adams, W. W.: Photoprotection and other responses of plants to high light stress, Annu. Rev. Pant Physiol. Plant Mol. Biol., 43, 599-626, 1992.

Demmig-Adams, B. and Adams, W. W.: The role of xantophyll cycle carotenoids in the protection of photosynthesis, Trends Plant Sci., 1, 21-26, 1996.

Dolman, a. J., Moors, E. J., and Elbers, J. a.: The carbon uptake of a mid latitude pine forest growing on sandy soil, Agr. Forest Meteorol., 111, 157-170, doi:10.1016/S0168-1923(02)00024-2, 2002.

Ensminger, I., Berninger, F., and Streb, P.: Response of photosynthesis to low temperature, in: Terrestrial Photosynthesis in a Changing Environment - A Molecular, Physiological and Ecological Approach, edited by: Flexas, J., Loreto, F., and Medrano, H., Cambridge University Press, Cambridge, 272-289, 2012.

Epron, D. and Dreyer, E.: Effects of severe dehydration on leaf photosynthesis in Quercus petruea (Matt.) Liebl.: photosystem II efficiency, photochemical and nonphotochemical fluorescence quenching and electrolyte leakage, Tree Physiol., 10, 273-284, 1992.

Espelta, J. M., Sabaté, S., and Retana, J.: Resprouting dynamics, in: Ecology of Mediterranean Evergreen Oak Forests, edited by: Rodà, F., Retana, J., Gracia, C. A., and Bellot, J., 61-71, 1999.

Farquhar, G. D. and Sharkey, T. D.: Stomatal conductance and photosynthesis, Annu. Rev. Plant Physiol., 33, 317-345, doi:10.1146/annurev.pp.33.060182.001533, 1982.

Farquhar, G. D., von Caemmerer, S., and Berry, J. A.: A biochemical model of photosynthesis $\mathrm{CO}_{2}$ assimilation in leaves of $\mathrm{C} 3$ species, Planta, 149, 78-90, 1980.

Flexas, J., Badger, M., Chow, W., Medrano, H., and Osmond, C.: Analysis of the relative increase in photosynthetic $\mathrm{O}$ uptake when photosynthesis in grapevine leaves is inhibited following low night temperatures and/or water stress, Plant Physiol., 121, 675684, 1999.

Flexas, J., Diaz-Espejo, A., Galmés, J., Kaldenhoff, R., Medrano, H., and Ribas-Carbo, M.: Rapid variations of mesophyll conductance in response to changes in $\mathrm{CO}_{2}$ con- 
centration around leaves, Plant. Cell Environ., 30, 1284-1298, doi:10.1111/j.1365-3040.2007.01700.x, 2007.

Flexas, J., Escalona, J. M. and Medrano, H.: Down-regulation of photosynthesis by drought under field conditions in grapevine leaves, Aust. J. Plant Physiol., 25(??), 893, doi:10.1071/PP98054, 1998.

Flexas, J., Ribas-Carbó, M., Diaz-Espejo, A., Galmés, J., and Medrano, H.: Mesophyll conductance to $\mathrm{CO}_{2}$ : current knowledge and future prospects, Plant. Cell Environ., 31, 602-621, doi:10.1111/j.1365-3040.2007.01757.x, 2008.

Flexas, J., Loreto, F., and Medrano, H.: Terrestrial photosynthesis in a changing environment - a molecular, physiological and ecological approach, edited by: Flexas, J., Loretto, F., and Medrano, H., Cambridge University Press, Cambridge, 2012.

Friend, A. D.: Terrestrial plant production and climate change, J. Exp. Bot., 61, 1293-309, doi:10.1093/jxb/erq019, 2010.

Fryer, M. J., Andrews, J. R., Oxborough, K., Blowers, D. A., and Baker, N. R.: Relationship between $\mathrm{CO}_{2}$ assimilation, photosynthetic electron transport, and active $\mathrm{O}_{2}$ metabolism in leaves of maize in the field during periods of low temperature, Plant Physiol., 116, 571-580, 1998.

García-Plazaola, J. I., Artetxe, U., and Becceril, María, J.: Diurnal changes in antioxidant and carotenoid composition in the Mediterranean schlerophyll tree Quercus ilex (L.) during winter, Plant Sci., 143, 125-133, 1999a.

García-Plazaola, J. I., Artetxe, U., Duñabeitia, M. K., and Becerril, J. M.: Role of photoprotective systems of Holm-Oak (Quercus ilex) in the adaptation to winter conditions, J. Plant Physiol., 155, 625-630, doi:10.1016/S0176-1617(99)80064-9, 1999b.

García-Plazaola, J. I., Faria, T., Abadia, J., Abadia, A., Chaves, M. M. and Pereira, J. S.: Seasonal changes in xanthophyll composition and photosynthesis of cork oak (Quercus suber L.) leaves under mediterranean climate, J. Experimantal Bot., 48(314), 1667-1674, 1997.

Garcia-Plazaola, J. I., Olano, J. M., Hernandez, A., and Becerril, J. M.: Photoprotection in evergreen Mediterranean plants during sudden periods of intense cold weather, Trees, 17, 285-291, doi:10.1007/s00468-002-0234-y, 2003a.

Garcia-Plazaola, J. I., Olano, J. M., Hernandez, A., and Becerril, J. M.: Photoprotection in evergreen Mediterranean plants during sudden periods of intense cold weather, Trees, 17, 285-291, doi:10.1007/s00468-002-0234-y, 2003b.

Genty, B., Briantais, J.-M., and Baker, N. R.: The relationship between the quantum yield of photosynthetic electron transport and quenching of chlorophyll fluorescence, Biochim. Biophys. Acta, 990, 87-92, 1989.

Gracia, C. A., Tello, E., Sabat, S., and Bellot, J.: GOTILWA: an integrated model of water dynamics and forest growth. Ecology of mediterranean evergreen oak forests, in: Ecology of Mediterranean Evergreen Oak Forests, edited by: Rodà, F., Retana, J., Gracia, C. A., and Bellot, J., Springer Berlin Heidelberg, Berlin, 163-178, 1999.

Gratani, L. and Ghia, E.: Adaptive strategy at the leaf level of Arbutus unedo L. to cope with Mediterranean climate, Flora, 197, 275-284, 2002a.

Gratani, L. and Ghia, E.: Changes in morphological and physiological traits during leaf expansion of Arbutus unedo, Environ. Exp. Bot., 48, 51-60, 2002b.
Gratani, L., Pesoli, P., Crescente, M. F., Aichner, K., and Larcher, W.: Photosynthesis as a temperature indicator in Quercus ilex L., Global Planet. Change, 24, 153-163, doi:10.1016/S0921-8181(99)00061-2, 2000.

Guidi, L. and Calatayud, A.: Non-invasive tools to estimate stressinduced changes in photosynthetic performance in plants inhabiting Mediterranean areas, Environ. Exp. Bot., 103, 42-52, doi:10.1016/j.envexpbot.2013.12.007, 2014.

Haldimann, P. and Feller, U.: Inhibition of photosynthesis by high temperature in oak (Quercus pubescens L.) leaves grown under natural conditions closely correlates with a reversible heat- dependent reduction of the activation state of ribulose-1, 5- bisphosphate carboxylase/oxy, Plant Cell Environ., 27, 1169-1183, 2004.

Harley, P. C., Loreto, F., Di Marco, G., and Sharkey, T. D.: Theoretical Considerations when Estimating the Mesophyll Conductance to $\mathrm{CO}_{2}$ Flux by Analysis of the Response of Photosynthesis to $\mathrm{CO}_{2}$, Plant Physiol., 98, 1429-1436, 1992.

Hikosaka, K., Murakami, A., and Hirose, T.: Balancing carboxylation and regeneration of ribulose-1,5- bisphosphate in leaf photosynthesis: temperature acclimation of an evergreen tree, Quercus myrsinaefolia, Plant Cell Environ., 22, 841-849, doi:10.1046/j.1365-3040.1999.00442.x, 1999.

Huner, N. P. A., Öquist, G., and Sarhan, F.: Energy balance and acclimation to light and cold, Trends Plant Sci., 3, 224-230, doi:10.1016/S1360-1385(98)01248-5, 1998.

Hurry, V., Strand, A., Furbank, R., and Stitt, M.: The role of inorganic phosphate in the development of freezing tolerance and the acclimatization of photosynthesis to low temperature is revealed by the pho mutants of Arabidopsis thaliana, Plant J., 24, 383396, 2000.

IPCC: IPCC, 2013: Summary for policymakers, in: Climate Change 2013: The Physical Science Basis, edited by: S. T. F., D. Qin, G.K. Plattner, M. Tignor, S. K. Allen, J. Boschung, A. Nauels, Y. Xia, V. Bex, and Midgley, P. M., Cambridge University Press, Cambridge (UK) and New York (USA), 2013.

Jordan, D. N. and Smith, W. K.: Simulated influence of leaf geometry on sunlight interception and photosynthesis in conifer needles, Tree Physiol., 13, 29-39, 1993.

Kang, C.-Y., Lian, H.-L., Wang, F.-F., Huang, J.-R., and Yang, H.Q.: Cryptochromes, phytochromes, and COP1 regulate lightcontrolled stomatal development in Arabidopsis, Plant Cell, 21, 2624-2641, doi:10.1105/tpc.109.069765, 2009.

Kok, B.: A critical consideration of the quantum yield of Chlorellaphotosynthesis, Enzymologia, 13, 1-56, 1948.

Kull, O. and Niinemets, U.: Variations in leaf morphometry and nitrogen concentration in Betula pendula Roth., Corylus avellana L., and Lonicera xylosteum L., Tree Physiol., 12, 311-318, 1993.

Kyparissis, A., Drilias, P., and Manetas, Y.: Seasonal fluctuations in photoprotective xanthophyll cycle) and photoselective (chlorophylls) capacity in eight Mediterranean plant species belonging to two different growth forms, Aust. J. Plant Physiol., 27, 265272, 2000.

Laisk, A., Oja, V., Rasulov, B., Rämma, H., Eichelmann, H., Kasparova, I., Pettai, H., and Padu, E.: A computer-operated routine of gas exchange and optical measurements to diagnose photosynthetic apparatus, Plant Cell Environ., 25, 923-943, 2002. 
Lambrev, P. H., Miloslavina, Y., Jahns, P., and Holzwarth, A. R.: On the relationship between non-photochemical quenching and photoprotection of Photosystem II, Biochim. Biophys. Acta, 1817, 760-769, doi:10.1016/j.bbabio.2012.02.002, 2012.

Levizou, E., Drilias, P., and Kyparissis, A.: Exceptional photosynthetic performance of Capparis spinosa L. under adverse conditions of Mediterranean summer, Photosynthetica, 42, 229-235, 2004.

Lusk, C. H., Wright, I., and Reich, P. B.: Photosynthetic differences contribute to competitive advantage of evergreen angiosperm trees over evergreen conifers in productive habitats, New Phytol., 160, 329-336, 2003.

Maestre, F. T. and Cortina, J.: Are Pinus halepensis plantations useful as a restoration tool in semiarid Mediterranean areas?, For. Ecol. Manage., 198, 303-317, doi:10.1016/j.foreco.2004.05.040, 2004.

Martinez-Ferri, E., Balaguer, L., Valladares, F., Chico, J. M., and Manrique, E.: Energy dissipation in drought-avoiding and drought-tolerant tree species at midday during the Mediterranean summer, Tree Physiol., 20, 131-138, doi:10.1093/treephys/20.2.131, 2000.

Martínez-Ferri, E., Manrique, E., Valladares, F., and Balaguer, L.: Winter photoinhibition in the field involves different processes in four co-occurring Mediterranean tree species, Tree Physiol., 24, 981-990, 2004.

Matesanz, S. and Valladares, F.: Ecological and evolutionary responses of Mediterranean plants to global change, Environ. Exp. Bot., 103, 53-67, doi:10.1016/j.envexpbot.2013.09.004, 2014.

Maxwell, K. and Johnson, G. N.: Chlorophyll fluorescence - a practical guide, J. Exp. Bot., 51, 659-668, 2000.

Meinzer, F. C., Johnson, D. M., Lachenbruch, B., McCulloh, K. A. and Woodruff, D. R.: Xylem hydraulic safety margins in woody plants: coordination of stomatal control of xylem tension with hydraulic capacitance, Funct. Ecol., 23, 922-930, doi:10.1111/j.1365-2435.2009.01577.x, 2009.

Mitrakos, K.: A theory for Mediterranean plant life, Acta Oecologica/Oecologia Plant., 1, 245-252, 1980.

Mott, K. A. and Buckley, T. N.: Stomatal heterogeneity, J. Experimantal Bot., 49(March), 407-417, 1998.

Mott, K. A. and Buckley, T. N.: Patchy stomatal conductance: emergent collective behaviour of stomata, Trends Plant Sci., 1385, 258-262, 2000.

Mulo, P., Sakurai, I., and Aro, E.-M.: Strategies for psbA gene expression in cyanobacteria, green algae and higher plants: from transcription to PSII repair, Biochim. Biophys. Acta, 1817, 247257, doi:10.1016/j.bbabio.2011.04.011, 2012.

Munné-Bosch, S. and Peñuelas, J.: Drought-induced oxidative stress in strawberry tree (Arbutus unedo L.) growing in Mediterranean field conditions, Plant Sci., 166, 1105-1110, doi:10.1016/j.plantsci.2003.12.034, 2004.

Niinemets, Ü., Oja, V., and Kull, O.: Shape of leaf photosynthetic electron transport versus temperature response curve is not constant along canopy light gradients in temperate deciduous trees, Plant. Cell Environ., 22, 1497-1513, doi:10.1046/j.13653040.1999.00510.x, 1999.

Niinemets, Ü., Cescatti, A., Rodeghiero, M., and Tosens, T.: Leaf internal diffusion conductance limits photosynthesis more strongly in older leaves of Mediterranean evergreen broad-leaved species, Plant Cell Environ., 28, 1552-1566, doi:10.1111/j.13653040.2005.01392.x, 2005.

Niinemets, Ü., Cescatti, A., Rodeghiero, M., and Tosens, T.: Complex adjustments of photosynthetic potentials and internal diffusion conductance to current and previous light availabilities and leaf age in Mediterranean evergreen species Quercus ilex, Plant Cell Environ., 29, 1159-1178, doi:10.1111/j.13653040.2006.01499.x, 2006.

Niinemets, U., Flexas, J., and Peñuelas, J.: Evergreens favored by higher responsiveness to increased $\mathrm{CO}_{2}$, Trends Ecol. Evol., 26, 136-42, doi:10.1016/j.tree.2010.12.012, 2011.

Ninyerola, M., Pons, X., and Roure, J. M.: A methodological approach of climatological modelling of air temperature and precipitation, Int. J. Climatol., 20, 1823-1841, 2000.

Ogaya, R. and Peñuelas, J.: Comparative seasonal gas exchange and chlorophyll fluorescence of two dominant woody species in a Holm Oak Forest, Flora, 198, 132-141, 2003.

Ogaya, R. and Peñuelas, J.: Leaf mass per area ratio in Quercus ilex leaves under a wide range of climatic conditions. The importance of low temperatures, Acta Oecologica, 31(??), 168-173, doi:10.1016/j.actao.2006.07.004, 2007.

Ogaya, R. and Peñuelas, J.: Leaf mass per area ratio in Quercus ilex leaves under a wide range of climatic conditions. The importance of low temperatures, Acta Oecol., 31, 168-173, doi:10.1016/j.actao.2006.07.004, 2007.

Oliveira, G. and Peñuelas, J.: Comparative photochemical and phenomorphological responses to winter stress of an evergreen (Quercus ilex L.) and a semi-deciduous (Cistus albidus L.) Mediterranean woody species, Acta Oecologica, 21, 97-107, 2000.

Oliveira, G. and Peñuelas, J.: Effects of winter cold stress on photosynthesis and photochemical efficiency of PSII of the Mediterranean Cistus albidus L., and Quercus ilex L., Plant Ecol., 175, 179-191, 2004.

Onoda, Y., Hikosaka, K., and Hirose, T.: Seasonal change in the balance between capacities of RuBP carboxylation and RuBP regeneration affects $\mathrm{CO}_{2}$ response of photosynthesis in Polygonum cuspidatum., J. Exp. Bot., 56(412), 755-63, doi:10.1093/jxb/eri052, 2005.

Öquist, G., and Huner, N. P. A.: Photosynthesis of overwintering evergreen plants, Annu. Rev. Plant Biol., 54, 329-55, doi:10.1146/annurev.arplant.54.072402.115741, 2003.

Orshan, G.: Approaches to the definition of Mediterranean growth forms, in: Mediterranean Type-Ecosystems - the Role of Nutrients, edited by: Kruger, F. J., Mitchell, D. T., and Jarvis, J. U. M., 86-100, Springer-Verlag, Berlin, Heidelberg, 1983.

Peñuelas, J. and Filella, I.: Responses to a Warming World, Science (80), 294, 794-795, doi:10.1126/science.1066860, 2001.

Peñuelas, J., Sardans, J., Estiarte, M., Ogaya, R., Carnicer, J., Coll, M., Barbeta, A., Rivas-Ubach, A., Llusià, J., Garbulsky, M., Filella, I., and Jump, A. S.: Evidence of current impact of climate change on life: a walk from genes to the biosphere, Glob. Change Biol., 19, 2303-2338, doi:10.1111/gcb.12143, 2013.

Reich, P. B., Ellsworth, D. S., and Walters, M. B.: Leaf structure (specific leaf area) modulates photosynthesis-nitrogen relations: evidence from within and across species and functional groups, Funct. Ecol., 12, 948-958, doi:10.1046/j.13652435.1998.00274.x, 1998. 
Reichstein, M., Tenhunen, J. D., Roupsard, O., Ourcival, J.-M., Rambal, S., Dore, S., and Valentini, R.: Ecosystem respiration in two Mediterranean evergreen Holm Oak forests: drought effects and decomposition dynamics, Funct. Ecol., 16, 27-39, doi:10.1046/j.0269-8463.2001.00597.x, 2002.

Sabaté, S. and Gracia, C. A.: Water processes in trees: transpiration and photosynthesis, in: Water for Forests and People in the Mediterranean - What Science Can Tell Us, edited by: Birot, Y., Gracia, C. A., and Palahí, M., European Forest Institut, Joensuu, available at: http://www.efi.int/portal/virtual_ library/publications/what_science_can_tell_us/, 72-75, 2011.

Sabaté, S., Sala, A., and Gracia, C. A.: Leaf Traits and Canopy Organisation, in: Ecology of Mediterranean Evergreen Oak Forests, edited by: Rodà, F., Retana, J., Gracia, C. A., and Bellot, J., Springer, Berlin, Heidelberg, 121-131, 1999.

Sanchez-Humanes, B. and Espelta, J. M.: Increased drought reduces acorn production in Quercus ilex coppices: thinning mitigates this effect but only in the short term, Forestry, 84, 73-82, doi:10.1093/forestry/cpq045, 2011.

Savé, R., Castell, C., and Terrades, J.: Gas Exchange and Water Relations, in Ecology of Mediterranean Evergreen Oak Forests, edited by: Rodà, F., Retana, J., Gracia, C. A., and Bellot, J., Springer, Berlin Heidelberg, 135-144, 1999.

Sharkey, T. D.: Photosynthesis in intact leaves of C3 plants: Physics, physiology and rate limitations., Bot. Rev., 51, 53-105, 1985.

Somot, S., Sevault, F., Déqué, M., and Crépon, M.: 21st century climate change scenario for the Mediterranean using a coupled atmosphere-ocean regional climate model, Glob. Planet. Change, 63, 112-126, doi:10.1016/j.gloplacha.2007.10.003, 2008.

Specht, R. L.: A comparison of the sclerophyllous vegetation characteristics of Mediterranean type climates in France, California, and southern Australia, I. Structure, morphology, and succession, Aust. J. Bot., 17, 277-292, 1969.

Taz, L. and Zeiger, E.: Plant Physiology, 5th edn., edited by: Taz, L. and Zeiger, E. Sinauer Associates, Inc., Sunderland, 2010.

Terashima, I. and Hikosaka, K.: Comparative ecophysiology of leaf and canopy photosynthesis, Plant Cell Environ., 18, 1111-1128, 1995.

Tretiach, M., Bolognini, G., and Rondi, A.: Photosynthetic activity of Quercus ilex at the extremes of a transect between Mediterranean and submediterranean vegetation (Trieste-NE Italy), Flora, 192, 369-378, 1997.

Turnbull, M. H., Whitehead, D., Tissue, D. T., Schuster, W. S. F., Brown, K. J., and Griffin, K. L.: Scaling foliar respiration in two contrasting forest canopies, Funct. Ecol., 17, 101-114, doi:10.1046/j.1365-2435.2003.00713.x, 2003.

Valladares, F. and Niinemets, Ü.: Shade tolerance, a key plant feature of complex nature and consequences, Annu. Rev. Ecol. Evol. S., 39, 237-257, doi:10.1146/annurev.ecolsys.39.110707.173506, 2008.
Valladares, F. and Niinemets, Ü.: Shade Tolerance, a Key Plant Feature of Complex Nature and Consequences, Annu. Rev. Ecol. Evol. Syst., 39, 237-257, doi:10.1146/annurev.ecolsys.39.110707.173506, 2008.

Valladares, F., Zaragoza-Castells, J., Sánchez-Gómez, D., Matesanz, S., Alonso, B., Portsmuth, A., Delgado, A., and Atkin, O. K.: Is shade beneficial for mediterranean shrubs experiencing periods of extreme drought and late-winter frosts?, Ann. Bot., 102, 923-933, doi:10.1093/aob/mcn182, 2008.

Vass, I.: Molecular mechanisms of photodamage in the Photosystem II complex., Biochim. Biophys. Acta, 1817, 209-217, doi:10.1016/j.bbabio.2011.04.014, 2012.

Vaz, M., Maroco, J., Ribeiro, N., Gazarini, L. C., Pereira, J. S., and Chaves, M. M.: Leaf-level responses to light in two co-occurring Quercus (Quercus ilex and Quercus suber): leaf structure, chemical composition and photosynthesis, Agroforestry Systems, 82, 173-181, doi:10.1007/s10457-010-9343-6, 2011.

Verhoeven, A.: Sustained energy dissipation in winter evergreens, New Phytol., 201, 57-65, doi:10.1111/nph.12466, 2014.

Werner, C., Correia, O., and Beyschlag, W.: Characteristic patterns of chronic and dynamic photoinhibition of different functional grops in a Mediterranean ecosystem, Funct. Plant Biol., 29, 991011, 2002.

Wullschleger, S. D.: Biochemical limitations to carbon assimilation in C3 plants - a retrospective analysis of the $\mathrm{j}$ curves from 109 species, J. Experimantal Bot., 44, 907-920, 1993.

Yin, X., Struik, P. C., Romero, P., Harbinson, J., Evers, J. B., van der Putten, P. E. L., and Vos, J.: Using combined measurements of gas exchange and chlorophyll fluorescence to estimate parameters of a biochemical $\mathrm{C}$ photosynthesis model: a critical appraisal and a new integrated approach applied to leaves in a wheat (Triticum aestivum) canopy., Plant. Cell Environ., 32, 448-464, doi:10.1111/j.1365-3040.2009.01934.x, 2009.

Yin, X., Sun, Z., Struik, P. C., and Gu, J.: Evaluating a new method to estimate the rate of leaf respiration in the light by analysis of combined gas exchange and chlorophyll fluorescence measurements, J. Exp. Bot., 62, 3489-3499, doi:10.1093/jxb/err038, 2011.

Zaragoza-Castells, J., Sánchez-Gómez, D., Valladares, F., Hurry, V., and Atkin, O. K.: Does growth irradiance affect temperature dependence and thermal acclimation of leaf respiration? Insights from a Mediterranean tree with long-lived leaves, Plant. Cell Environ., 30, 820-833, doi:10.1111/j.1365-3040.2007.01672.x, 2007. ?

Zavala, M. A., Espelta, J. M., and Retana, J.: Constraints and tradeoffs in Mediterranean plant communities: the case of Holm OakAleppo Pine forests, Bot. Rev., 66, 119-149, 2000. 